\title{
Productivity Growth across Spanish Regions and Industries: A Production-Frontier Approach*
}

\author{
Oleg Badunenko $\quad$ Diego Romero-Ávila ${ }^{\ddagger}$
}

${ }^{*}$ We thank conference participants at the 2010 European Economic Association Annual Meeting (Glasgow), XXXV Simposio de Análisis Económico (Madrid, 2010) and XIII Encuentro de Economía Aplicada (Sevilla, 2010) for helpful suggestions. We are particularly indebted to the Editor and two referees of this journal for valuable comments that led to a substantial improvement of the paper. Diego Romero-Ávila acknowledges financial support from the Spanish Ministry of Science and Technology through grant ECO2009-13357 and from the Andalusian Council of Innovation and Science under Excellence Project SEJ-4546.

${ }^{\dagger}$ University of Cologne, Cologne Graduate School in Management, Economics and Social Sciences, RichardStrauss-Str. 2, 50931, Cologne, Germany. Phone: +49.221.470.1285. Fax: +49.221.470.1229, E-mail: obadunen@uni-koeln.de.

${ }^{\ddagger}$ Universidad Pablo de Olavide, Departmento de Economía, Métodos Cuantitativos e Historia Económica, Carretera de Utrera, Km. 1, Sevilla, 41013, Spain, Tel.: +34954348381, Fax: +34954349339, E-mail: dromtor@upo.es. 


\title{
Productivity Growth across Spanish Regions and Industries: A Production-Frontier Approach
}

\begin{abstract}
This paper decomposes labor productivity growth into components attributable to technological change, technological catch-up, capital deepening and human capital accumulation. This is done through a production-frontier approach applied to Spanish data disaggregated along regional and sectoral dimensions. We show that capital deepening is the primary contributor to productivity growth, closely followed by human capital and technological change; widespread efficiency losses substantially impede productivity growth; productivity convergence is driven by higher efficiency losses exhibited by rich regions; analysis of sectoral data shows marked differences in productivity performance; and aggregate productivity growth is driven by intrasectoral productivity dynamics rather than structural change.
\end{abstract}

Keywords: Sectoral Analysis, Spanish Regions, Productivity Growth and Convergence, Data Envelopment Analysis, Distributional Analysis

JEL: D24, O47, R11 


\section{Introduction}

Since the seminal work of KUMAR and RUSSELL (2002), there has been a long-standing debate over the role of technology versus physical capital deepening in explaining labor productivity improvements across countries. ${ }^{1}$ Two main reasons are responsible for this interest. First, the different predictions of Neoclassical growth theory pioneered by the work of SoLOW (1956) and CASS (1965), and endogenous growth theory regarding the primary source of growth. While the former considers exogenous technological progress as the source of permanent growth changes, endogenous growth models like those of Romer (1986) and LUCAS (1988) point to physical and human capital accumulation as the main engines of growth. ${ }^{2}$ Second, the increasing availability of cross-country datasets such as the Penn World Table (Summers and Heston (1991)) has allowed the empirical analysis of these issues over relatively long periods.

Using a nonparametric frontier approach, some studies have attempted to determine the relative growth contributions of technological change, technological catch-up and factor accumulation for different samples of countries. KUMAR and RUSSELL (2002) find that both growth and international income polarization are driven primarily by capital deepening (i.e. changes in the physical capital to labor ratio) in a wide sample of 57 countries over the period 1965-1990. HEnderson and Russell (2005) further extend Kumar and Russeld (2002) study by adding human capital as an additional input into production. Their analysis indicates that 1) labor productivity growth is driven predominantly by physical and human capital accumulation, and 2) international polarization is caused primarily by technological catch-up via efficiency changes.

Despite this considerable effort to investigate these issues at the aggregate level, not much work has been conducted at the sectoral level within a specific country or across countries. MARGARITIS et al. (2007) constitute a clear exception. By decomposing labor productivity growth into technological change, efficiency changes and capital deepening for a panel of 19 OECD countries over the period 1979-2002, they find physical capital accumulation and technological change to be the first and second growth engines, respectively. Their analysis of the contribution of productivity growth within industries and sectoral composition indicates that aggregate productivity changes are predominantly driven by within sectoral effects with very little contribution resulting from structural change due to sectoral shifts.

In the parallel literature of convergence, the role of technology has been largely ignored. Quoting BERNARD and JONES (1996c), 'to the extent that the adoption and accumulation of technologies is important for convergence, the empirical convergence literature to date is misguided.' They then called for future work on growth and convergence placing more emphasis on technology. In addition, they point out the need to move to sectoral level analysis to examine convergence. ${ }^{3}$ As they note, the analysis of the manufacturing sector should be particularly relevant given that most $R \& D$ and international trade takes place in this sector. Unexpectedly however, BERNARD and JONES (1996b) find no evidence of labor productivity convergence in 
the manufacturing sector across 14 OECD countries from 1970 to 1987. This contrasts with the finding of convergence in the services sector and the aggregate. These results carry over to the analysis of convergence in multifactor productivity, as shown by BERNARD and JONES (1996a).

The objective of this paper is to develop a nexus between two important literatures: the deterministic frontier production function literature based on the pioneering work of FARRELL (1957) and the investigation of the sources of aggregate labor productivity growth by disaggregating the data along two dimensions: at the sectoral and regional levels. Hence, to the best of our knowledge, this is the first study applying the production frontier approach of FäRE et al. (1994) and KumAR and RUSSELL (2002) to examining the sources of aggregate labor productivity growth using this double level of disaggregation. More specifically, we will focus on the Spanish economy over the period 1980-2003 as a laboratory for the analysis of labor productivity dynamics. Unlike most industrialized countries, with the possible exception of the United States, we have access to consistent and detailed data series for the private productive sector on gross value added at factor cost, employment, physical capital stocks and several proxies for human capital stocks across both important dimensions: regional and sectoral. The advantage of using this nonparametric production frontier approach is that is a purely data-driven method, which neither requires specification of any particular production function technology (e.g. Cobb-Douglas or CES), nor the existence of perfectly competitive markets or Hicks-neutral technological change. Unlike the standard regression-based growth accounting literature, this framework allows us to distinguish between catching-up (movements towards the frontier) and technological change (shifts in the frontier).

A related paper that focuses on the effect of efficiency changes on convergence of labor productivity rather than on the sources of productivity growth is that of MAUDOS et al. (2000b). Applying Data Envelopment Analysis to Spanish regional data for five sectors over the period 1964-1993, they find that intra-sector efficiency gains and to a lower extent efficiency variations due to structural change in productive specialization across regions were a significant source of convergence for most of the period analyzed. Our paper differs from the former in several respects (beyond the analysis of a different time period and the use of a more consistent dataset). First, our analysis not only calculates efficiency scores per se at the sectoral level for each region, but also tries to investigate the relative contribution of other sources of labor productivity growth such as technological change, capital deepening and human capital accumulation. Second, we try to shed some light on the effect of each factor on productivity convergence not only through simple cross-sectional regressions, but also by examining the evolution of the entire cross-section distribution and the degree to which each of the four components of productivity change accounts for such productivity dynamics. This is done through the strategy of constructing counterfactual labor productivity distributions to isolate the effect of each component and comparing it with the actual distribution. In addition, we investigate whether intrasectoral productivity dynamics and/or structural change -explained by shifting sectoral shares of employment- have affected regional and aggregate labor productivity performance. 
Our results indicate that (1) technological change is clearly not Hicks-neutral; (2) capital deepening is the primary contributor to labor productivity growth, closely followed by human capital accumulation and technological change; (3) widespread efficiency losses appear to substantially inhibit productivity growth; (4) simple convergence regressions as well as the examination of the cross-region distribution of labor productivity in terms of the quadripartite decomposition support the existence of convergence in labor productivity, mainly driven by the higher efficiency losses exhibited by rich regions relative to poor ones; (5) analysis of sectoral data shows marked differences in productivity performance as well as in the contribution of the four components across sectors; (6) aggregate productivity growth is mainly driven by intrasectoral productivity dynamics - primarily in manufacturing and agriculture-rather than structural change; (7) for both total industry and the five sectors separately, productivity dynamics during the subperiod 1980-1994 appear to predominantly drive the outcome for the whole period.

The rest of the article is structured as follows: Section 2 briefly reviews the literature and describes the data. Section 3 presents the statistical methods behind the nonparametric frontier approach of HENDERSON and RUSSELL (2005) and the quadripartite decomposition of labor productivity into its components. Section 4 presents the results for total industry and Section 5 does so for the five sectors considered. It also sheds some light on the contribution to aggregate labor productivity growth attributable to intra-sectoral dynamics and sectoral shifts. Section 6 discusses our results in light of previous findings. Section 7 summarizes the main findings and then concludes.

\section{Data Issues and Brief Literature Review}

\subsection{Brief Literature Review}

The great availability of regional and sectoral data for the Spanish economy explains the existence of some previous studies investigating, from other perspectives, growth and convergence issues in Spain. As a matter of fact, TorTOSA-Ausina et al. (2005) use distribution dynamics techniques to investigate convergence across the Spanish provinces over the past decades. Their results indicate the existence of convergence in labor productivity, TFP and capital intensity, while the convergence patterns in per capita income are less marked. Using QUAH (1996)'s distributional approach, LAMO (2000) examines the convergence dynamics of the cross-section distribution of biannual GDP per capita across the 50 Spanish provinces over the period 19551991. Her analysis did not render evidence of income convergence and, contrary to expectations, interregional migration appeared to impede convergence.

Using Malmquist productivity indexes, MaUdos et al. (2000a) investigate the contribution of factor accumulation, technical change and efficiency on labor productivity convergence in OECD countries. They find evidence that technical change contributed to divergence over the period 1975-1990, which was partly counteracted by the forces towards convergence due to the 
greater rate of accumulation of phvsical capital by poorer countries. In addition. Escribá and MurGui (2001) investigate the dynamics of growth and convergence in productivity across the Spanish regions over the period 1980-1995 using sectoral level data, but through conventional growth accounting techniques. They find multifactor productivity changes to be the main determinant of convergence in labor productivity. Within sectoral dynamics appear to explain $56 \%$ of convergence in TFP, while the rest is explained by sectoral shifts leading to structural change. However, it is important to point out that this approach cannot distinguish between technological change (caused by technological innovation) and efficiency changes (caused by technological catch-up).

Finally, employing Data Envelopment Analysis in similar spirit to Kumar and RUSSELL (2002), SALINAS JimÉneZ (2003a) and SALINAS JimÉNEZ (2003b) decompose labor productivity growth into the contributions attributable to efficiency changes, technological change and physical capital accumulation for the aggregate Spanish economy and four main sectors (agriculture, manufacturing, construction and services) over the period 1965-1995. The main differences of the analysis conducted in these papers relative to ours are the following. First, she investigates a totally different time period, which does not cover our second subperiod 1995-2003 where productivity growth and its sources appear to behave completely different from previous decades (see subsection 4.5 below). Second, unlike our study that employs a consistent dataset called BD.MORES.2000 which is derived directly from official regional accounts data, her data on gross value added, physical capital stocks and employment stem from Fundación Banco Bilbao Vizcaya that provides this information on a biennial basis. Third, unlike our analysis, she does not conduct the productivity growth decomposition for the 17 regions, thus only reporting results for the aggregate economy and four main sectors. Fourth -and key for the difference in results across studies-, she fails to include any measure of human capital accumulation in the productivity decomposition. Not surprisingly, the inclusion of several proxies for human capital accumulation renders significant differences throughout our investigation relative to her analysis. ${ }^{4}$ Fifth, in the distributional analysis she did not use nonparametric developments like those of $\operatorname{LI}(1996)$ and $\mathrm{LI}$ (1999), which are necessary to make correct inferences regarding the factors behind the shifts and changes in shape of the productivity distribution over time.

\subsection{Data Description}

The dataset employed for gross value added at factor cost (GVA hereafter), employment and net physical capital stock series is BD.MORES.2000 (see DABÁN et al. (2002) and DE BusTOS et al. (2008)). ${ }^{5}$ This database provides magnitudes expressed in 2000 Euros for 17 regions (comunidades autónomas) following the sectoral classification R-17. We follow the extant literature by focusing on the private productive sector, i.e. excluding the housing and public sectors. Hence, we exclude (1) imputed rents (alquileres imputados) and non-retail services (servicios no destinados a la venta) from GVA, and (2) residential structures and public capital from the net 
stock of physical capital. Likewise, employment and human capital measures exclude the public sector and the residential sector. The net stocks of physical capital are estimated using the standard perpetual inventory method with depreciation rates and initial stocks in 1964 specific to each sector. In the estimation, they employ sector-specific deflators for gross fixed capital formation. ${ }^{6}$

Unlike alternative data sources, this dataset employs region-specific and sector-specific deflators to compute the disaggregated GVA figures for the period $1980-2003{ }^{7}$ In our analysis we follow previous work by aggregating into five main sectors: agriculture (including fishery), manufacturing (excluding the energy sector), energy, construction and market services (henceforth services). The advantages of using this dataset are that: 1) it is constructed on the basis of official data sources like the Regional Accounts (with base year 2000) provided by the Spanish Statistical Institute (Instituto Nacional de Estadistica), and 2) it is carefully and consistently constructed on the basis of all available primary information, which provides full comparability across regions, sectors and over time.

As a measure of human capital for aggregate (total industry), regions and sectors, we employ the average years of schooling in the employed population provided by the Valencian Institute for Economic Research (IVIE) in collaboration with Bancaja (see SERRANO and SOLER (2008)). The length of each schooling cycle is that associated with the educational law called LOGSE. In addition, we adopt the HALL and Jones (1999) procedure and the PSACHAROPOULOS (1994) survey of wage equations evaluating the returns to education to transform these average years of schooling data into a human capital index. In particular, let $\epsilon_{t}^{i}$ represent the average number of years of education of the adult population in region $i$ at time $t$ and define labor in efficiency units in region $i$ at time $t$ by

$$
\widehat{L}_{t}^{i}=H_{t}^{i} L_{t}^{i}=h\left(\epsilon_{t}^{i}\right) L_{t}^{i}=e^{\phi\left(\epsilon_{t}^{i}\right)} L_{t}^{i}
$$

where $\phi$ is a piecewise linear function, with a zero intercept and a slope of 0.134 through the fourth year of education, 0.101 for the next four years, and 0.068 for education beyond the eighth year. Clearly, the rate of return to education (where $\phi$ is differentiable) is

$$
\frac{d \ln h\left(\epsilon_{t}^{i}\right)}{d \epsilon_{t}^{i}}=\phi^{\prime}\left(\epsilon_{t}^{i}\right)
$$

and $h(0)=1$.

Taken as a whole, the data employed can be thought of as the richest dataset allowing for an analysis of the sources of growth and convergence with such a high degree of detail (sectoral and regional), which would not be feasible for any other country, except probably the U.S. economy. Table 1 shows the descriptive statistics for each of our main variables (GVA, employment, net physical capital stock and the human capital index) for each region and Spain as well as the abbreviation used for each region. 


\section{Methodology}

We follow the methodology of HENDERSON and RUSSELL (2005) to decompose labor productivity change into components attributable to (i) efficiency changes (technological catch-up), (ii) technological change, (iii) capital deepening, and (iv) human capital accumulation. More specifically, we use a nonparametric approach to efficiency measurement, Data Envelopment Analysis (DEA), which rests on assumptions of free disposability to envelope the data in the smallest convex cone, the upper boundary of which is the "best-practice" frontier. To give a short description of the methodology ${ }^{8}$ we start off by specifying the world-wide technology that contains four macroeconomic variables: aggregate out and three inputs - labor, physical capital, and human capital. We adopt a standard approach in the macroeconomic literature and assume that human capital enters the technology as a multiplicative augmentation of physical labor input, so that our $N T$ observations are $\left\langle Y_{i t}, K_{i t}, \hat{L}_{i t}\right\rangle, t=1,2, \ldots, T, i=1,2, \ldots, N$, where $\hat{L}_{i t}=L_{i t} H_{i t}$ is the amount of labor input measured in efficiency units in region $i$ at time $t$. The constant returns to scale ${ }^{9}$ technology in period $t$ is constructed by using all the data up to that point in time as

$$
\mathcal{T}_{t}=\left\{\begin{array}{rr}
\langle Y, \hat{L}, K\rangle \in \Re_{+}^{3} \quad \mid \quad \leq \sum_{\tau \leq t} \sum_{i} z_{i \tau} Y_{i \tau}, \\
\hat{L} \geq \sum_{\tau \leq t} \sum_{i} z_{i \tau} \hat{L}_{i \tau}, \\
K \geq \sum_{\tau \leq t} \sum_{i} z_{i \tau} K_{i \tau}, \\
z_{i \tau} \geq 0 \quad \forall i, \tau
\end{array}\right\}
$$

where $z_{i \tau}$ are the activity levels. Notice that we have two separate summations. The latter refers to region while the former refers to time. Here the summation is over $\tau \leq t$. This implies that when calculating the technology in period $t$, the previous years technology are also available. That is, it is assumed that technologies available in previous years were not lost and were at disposal in later years.

The FARRELL (output-based) efficiency index for region $i$ at time $t$ relative to technology available at time $t$ is defined by

$$
E_{t}^{i t}\left(Y_{i t}, \hat{L}_{i t}, K_{i t}\right)=\min \left\{\lambda_{t}^{i t} \mid\left\langle Y_{i t} / \lambda_{t}^{i t}, \hat{L}_{i t}, K_{i t}\right\rangle \in \mathcal{T}_{t}\right\}
$$

This score is the inverse of the maximal proportional amount that output $Y_{i t}$ can be expanded while remaining technologically feasible $\left(\mathcal{T}_{t}\right)$, given the technology and input quantities.

Let $\hat{y}=Y / \hat{L}$ and $\hat{k}=K / \hat{L}$ be the ratios of output and capital, respectively, to effective labor. Letting $b$ and $c$ stand for the base period and current period respectively, the potential outputs per efficiency unit of labor in the two periods are defined by $\bar{y}_{b}\left(\hat{k}_{b}\right)=\hat{y}_{b} / e_{b}^{b}$ and $\bar{y}_{c}\left(\hat{k}_{c}\right)=\hat{y}_{c} / e_{c}^{c}$, 
where $e_{b}^{b}$ and $e_{c}^{c}$ are the values of the efficiency scores in the respective periods as calculated in Eq. (41) above. Hence,

$$
\frac{\hat{y}_{c}}{\hat{y}_{b}}=\frac{e_{c}^{c}}{e_{b}^{b}} \cdot \frac{\bar{y}_{c}\left(\hat{k}_{c}\right)}{\bar{y}_{b}\left(\hat{k}_{b}\right)} .
$$

Let $\tilde{k}_{c}=K_{c} /\left(L_{c} H_{b}\right)$ denote the ratio of capital to labor measured in efficiency units under the counterfactual assumption that human capital had not changed from its base period and $\tilde{k}_{b}=K_{b} /\left(L_{b} H_{c}\right)$ the ratio of capital to labor measured in efficiency units under the counterfactual assumption that human capital were equal to its current-period level. Then $\bar{y}_{b}\left(\tilde{k}_{c}\right)$ and $\bar{y}_{c}\left(\tilde{k}_{b}\right)$ are the potential output per efficiency unit of labor at $\tilde{k}_{c}$ and $\tilde{k}_{b}$ using the base-period and current-period technologies, respectively. By multiplying the numerator and denominator of Eq. (5) by $\left(\bar{y}_{b}\left(\hat{k}_{c}\right) \bar{y}_{b}\left(\tilde{k}_{c}\right)\right)^{1 / 2}\left(\bar{y}_{c}\left(\hat{k}_{b}\right) \bar{y}_{c}\left(\tilde{k}_{b}\right)\right)^{1 / 2}$, we obtain the decomposition of growth of $\hat{y}$

$$
\frac{\hat{y}_{c}}{\hat{y}_{b}}=\frac{e_{c}}{e_{b}} \cdot\left(\frac{\bar{y}_{c}\left(\hat{k}_{c}\right)}{\bar{y}_{b}\left(\hat{k}_{c}\right)} \frac{\bar{y}_{c}\left(\hat{k}_{b}\right)}{\bar{y}_{b}\left(\hat{k}_{b}\right)}\right)^{1 / 2} \cdot\left(\frac{\bar{y}_{b}\left(\tilde{k}_{c}\right)}{\bar{y}_{b}\left(\hat{k}_{b}\right)} \frac{\bar{y}_{c}\left(\hat{k}_{c}\right)}{\bar{y}_{c}\left(\tilde{k}_{b}\right)}\right)^{1 / 2} \cdot\left(\frac{\bar{y}_{b}\left(\hat{k}_{c}\right)}{\bar{y}_{b}\left(\tilde{k}_{c}\right)} \frac{\bar{y}_{c}\left(\tilde{k}_{b}\right)}{\bar{y}_{c}\left(\hat{k}_{b}\right)}\right)^{1 / 2} .
$$

Growth of productivity, $y_{t}=Y_{t} / L_{t}$, can be decomposed into growth of output per efficiency unit of labor and growth of human capital, $y_{c} / y_{b}=\left(\hat{y}_{c} / \hat{y}_{b}\right)\left(H_{c} / H_{b}\right)$, which can be extended using Eq. (6) to obtain the decomposition of labor productivity growth in the two periods into changes in efficiency, technology, the capital-labor ratio, and human capital accumulation:

$$
\begin{aligned}
\frac{y_{c}}{y_{b}} & =\frac{e_{c}}{e_{b}} \cdot\left(\frac{\bar{y}_{c}\left(\hat{k}_{c}\right)}{\bar{y}_{b}\left(\hat{k}_{c}\right)} \frac{\bar{y}_{c}\left(\hat{k}_{b}\right)}{\bar{y}_{b}\left(\hat{k}_{b}\right)}\right)^{1 / 2} \cdot\left(\frac{\bar{y}_{b}\left(\tilde{k}_{c}\right)}{\bar{y}_{b}\left(\hat{k}_{b}\right)} \frac{\bar{y}_{c}\left(\hat{k}_{c}\right)}{\bar{y}_{c}\left(\tilde{k}_{b}\right)}\right)^{1 / 2} \cdot\left[\left(\frac{\bar{y}_{b}\left(\hat{k}_{c}\right)}{\bar{y}_{b}\left(\tilde{k}_{c}\right)} \frac{\bar{y}_{c}\left(\tilde{k}_{b}\right)}{\bar{y}_{c}\left(\hat{k}_{b}\right)}\right)^{1 / 2} \frac{H_{c}}{H_{b}}\right] \\
& \equiv E F F \times T E C H \times K A C C \times H A C C .
\end{aligned}
$$

\section{Analysis of the Total Industry}

\subsection{Efficiency Analysis}

Figure 1 superimposes the estimated production frontiers, also presenting scatter plots of $\hat{y}$ (output per efficiency unit of labor) versus $\hat{k}$ (capital per efficiency unit of labor) for 1980 and 2003. The double kink on the 1980 production frontier indicates the existence of only two efficient regional economies (the Balearic Islands and Madrid). The frontier in 2003 is formed by the 1987 Madrid observation and 1985 Balearic Islands observation. Note that none of 2003 observations forms the 2003 frontier. This is because we have included all year observations to see who defines the 2003 frontier, following the 'technological non-implosion' argument. We adopt this approach (first suggested by DIEWERT (1980)) for constructing the countrywide technology that precludes such technological degradation, because it is conceivably difficult to support that regions lose blueprints and become less technologically competent over time. If we had not done 
so, technological regress would be imposed as the 2003 frontier (solid kinked line on Figure 1) would lie under the 1980 frontier (the dashed kinked line).

We can also observe that the production frontier shifted up from 1980 to 2003 but not by the same proportion for every value of the level of physical capital measured in efficiency units of labor. This implies that technological change was not Hicks-neutral. Rather, the largest shifts of the frontier occur at higher degrees of capitalization (from $\hat{k}$ greater than about 18,500), as implied by Harrod-neutral technological change. Thus, assuming Hicks-neutral technological change as done in conventional growth accounting studies would be misleading.

\section{[Insert Figure 1 about here]}

To assess the efficiency of regional economies, we examine their location relative to the frontier. The efficiency scores for each region in 1980 and 2003 are reported in the first two columns of Table 2. The last two rows present the unweighted and population-weighted averages across regions. Given the importance of weighting the outcome of each region by its size as stressed, among others, by TorTOSA-AUsina et al. (2005), we will centre on the results for the weighted average. This accounts to some extent for the heterogeneity present at the regional level, with regions like Andalusia having a population over 8 million inhabitants versus regions like the Balearic Islands, Cantabria, Rioja and Navarra with less than a million inhabitants.

On average, we observe that Spanish regional economies move further away from the bestpractice production frontier, since the efficiency score falls from 0.77 to 0.62 during the 24-year period. Except for Extremadura, whose efficiency index remains almost unaltered, the other regions experience important reductions in efficiency levels. ${ }^{10}$ This indicates that regions are not catching up to the frontier due to technological diffusion, and even the Balearic Islands and Madrid -that were technological leaders with scores equal to 1 in the initial year- have lost a lot of ground over the period under scrutiny. Despite this fact, Madrid is the least inefficient region with an efficiency score of 0.72 in 2003. Not surprisingly, Figure 2 shows a prominent shift to the left in the probability mass from a distribution containing a high variability of efficiency scores across regions and centered at about 0.75 to a much more concentrated distribution centered at about 0.60 . This supports the results shown in Table 2 pointing to the widespread fall in efficiency across regions between 1980 and 2003.

$$
\text { [Insert Figure } 2 \text { about here] }
$$

\subsection{Quadripartite Decomposition}

To gain a better understanding of the factors that contributed to the growth performance of the Spanish regions, we decompose labor productivity growth into components attributable to (1) efficiency changes, (2) technological change, (3) physical capital deepening and (4) human capital 
accumulation. The change in labor productivity of each region is reported in the third column of Table 2, while the contributions in percentage terms of changes in the four components appear in columns 4 to 7 of Table 2. These contributions in percentage terms can be easily transformed into indices using the formula $(P E R C E N T A G E / 100+1)$ so that Equation 7 holds. ${ }^{11}$

On average, labor productivity in Spain has increased by 36.2\% from 1980 to 2003, with efficiency changes impeding growth, on average, by almost 19\%. In contrast, the average contributions attributable to technological progress, capital deepening and human capital accumulation amount to $16 \%, 22 \%$ and $20 \%$, respectively. Thus, on average, physical capital accumulation has been the main engine of labor productivity growth in Spain, closely followed by human capital accumulation and technological progress. ${ }^{12}$ At the regional level, there is some evidence of spatial trends in regional productivity growth as those regions with labor productivity change above average are usually neighboring one another. As a matter of fact, Castilla-Leon neighbors the other above-average performers (Aragon, Asturias, Cantabria, Castilla-la-Mancha, Extremadura and Galicia) and some of these regions are adjacent to each other (for instance Asturias neighbors Galicia, Cantabria and Castilla-Leon). In regards to the contribution of each component at the regional level, physical capital accumulation appears to be the primary engine of growth in four regions (Canary Islands, Galicia, Madrid and Valencian Community) while human capital is the main driver of productivity growth in the remaining regions. ${ }^{13}$

\section{[Insert Table 2 about here]}

For the sake of completeness, we examine the impact of the four growth components on the convergence of output per worker across regions by regressing the change in labor productivity and its four components on the initial level of output per worker. ${ }^{14}$ As shown in Figure 3, regional convergence in labor productivity appears entirely driven by efficiency changes through the higher efficiency losses on the part of rich regions relative to poor ones. Since these preliminary conclusions are based on first-moment characterizations of the productivity distribution and are vulnerable to QUAH (1993)'s critique, we now turn to examine the evolution of the entire cross-section distribution of labor productivity.

\section{[Insert Figure 3 about here]}

\subsection{Distributional Analysis}

Labor productivity distributions obtained from nonparametric kernel-based density estimates appear in Figure 4. The solid and dashed curves represent the distribution of labor productivity in 1980 and 2003, respectively, with their corresponding mean values shown as vertical lines. As noted by, among others, TORTOSA-Ausina et al. (2005), if the probability mass is increasingly concentrated around a certain value, there would be evidence of convergence towards that value. 
By contrast, if the probability mass spreads out increasingly as given by a rise in the distance between the extreme values of the distribution, the outcome would be divergence.

It is evident that the distribution of labor productivity is unimodal both in the starting and ending years. In addition, the distribution has shifted to the right from a mean value of about 24,000 to a mean value of about 33,000 . It is also noticeable that the probability mass has become more concentrated around the new labor productivity mean, and the distance between the extreme values of the distribution has narrowed down. Both facts are consistent with the existence of some evidence of convergence, thus supporting the results from the simple convergence regressions presented above.

\section{[Insert Figure 4 about here]}

By employing the quadripartite decomposition of productivity growth, we will be able to explore the role of each of the four components in the transformation of the productivity distribution over the sample period, and in turn their influence on the growth and convergence of regional labor productivity. Towards this end, we follow the methodology of HENDERSON and Russell (2005) and rewrite Equation 7 as follows:

$$
y_{c}=(E F F \times T E C H \times K A C C \times H A C C) \times y_{b}
$$

Hence, the labor productivity distribution in 2003 can be constructed by consecutively multiplying the labor productivity distribution in 1980 by each of the four components. To isolate the impact of each component, we create counterfactual distributions by employing nonparametric kernel methods. In each panel of Figures 5-6, the solid (dashed) curve is the estimated 1980 (2003) distribution of output per worker and the solid (dashed) vertical line represents the 1980 (2003) mean value of output per worker, whereas the counterfactual distributions are shown as dotted curves (and the corresponding vertical dotted line represents the counterfactual mean). For instance, one can assess the shift of the labor productivity distribution due solely to capital deepening by examining the counterfactual distribution of the variable:

$$
y^{K}=K A C C \times y_{b}
$$

assuming no efficiency changes, technological change or human capital accumulation. This is shown in Panel A of Figure 5. We can observe that physical capital accumulation has shifted the probability mass to the right, thus causing an important increase in mean output per worker as reflected in the dotted vertical line. We can also infer that physical capital accumulation has made only some regions much richer, as the right tail of the counterfactual distribution now stretches beyond that of the 2003 income distribution.

We next include sequentially more components in the counterfactual distribution to isolate, sequentially, the effects of each component. Hence, when we include human capital in $y^{K}$, we 
have:

$$
y^{K H}=(K A C C \times H A C C) \times y_{b}=H A C C \times y^{K},
$$

drawn in Panel B of Figure 5, which isolates the joint effect of physical and human capital accumulation on the base period distribution. Besides a significant shift to the right in the distribution from a mean value about 29,000 to almost 35,000, the shape of the counterfactual distribution $y^{K H}$ is almost identical to that in Panel A, thus indicating that human capital accumulation has had little effect on the shape of the distribution. The additional effect of efficiency changes on the distribution $y^{K H}$ can be assessed as follows:

$$
y^{K H E}=(K A C C \times H A C C \times E F F) \times y_{b}=E F F \times y^{K H},
$$

drawn in Panel C of Figure 5. In this case, there is a significant shift to the left in the distribution, thus corroborating our previous findings pointing to efficiency losses as the main impediment to growth in labor productivity. This leads to offset the productivity gains obtained from human capital accumulation as reflected in the mean values of $y^{K H E}$ relative to $y^{K}$. Interestingly, we also observe a much higher probability mass concentration and lower spread in the counterfactual distribution $y^{K H E}$ than in $y^{K H}$. This clearly indicates that efficiency changes have been the main driver of convergence in productivity over the period 1980-2003, thus corroborating the results from convergence regressions showing that rich regions experience higher efficiency losses than poor ones. From Panel $\mathrm{C}$ we can also indirectly infer the positive contribution of technological change, as the difference between the counterfactual distribution $y^{K H E}$ and the distribution in 2003.

\section{[Insert Figures 5 and 6 about here]}

In Figure 6 we change the sequence of introducing the factors. We start with efficiency changes, followed by technological change and capital deepening. Panel A shows that, efficiency changes do not only shift dramatically the distribution to the left from a mean value of output per worker around 33,500 in 1980 to 20,000, but also lead to (higher) probability mass concentration and (lower) spread of the distribution -similar to the distribution in 2003. This, again, supports the fact that efficiency change has been the factor responsible for the observed regional convergence in productivity. Panel B, in turn, shows how the growth impediment from efficiency losses has been slightly higher than the productivity gains from technological progress, as reflected in a lower mean output per worker than in the base year. And, finally, Panel C shows the positive contribution of physical capital accumulation to productivity growth and indirectly the same result for human capital accumulation. Essentially the same results follow when we alter the ordering in the addition of the contribution of each component to the mix.

To complement the analysis of counterfactual distributions, we perform formal tests for the statistical significance of differences between the actual and counterfactual distributions. More specifically, we employ the test of LI (1996) as well as the bootstrap procedure of LI 
(1999) that was designed to calculate critical values for this test. ${ }^{15}$ In computing the test, we use the Gaussian kernel function and the SHEATHER and JonES (1991) procedure to select the optimal bandwidth. The application of this test will allow us to indirectly test for the statistical significance of the relative contribution of the four components of productivity change to variations in the distribution of labor productivity.

The first test in Table 3 indicates that the distributions in 1980 and 2003 are significantly different at the $1 \%$ level. The next four tests compare the actual distribution in 2003 with the counterfactual distribution, assuming that only one of the four components is introduced one at a time. The small $p$-values reflect that efficiency changes, technological change and capital deepening alone did not do much to statistically significantly shift the base period distribution towards the 2003 distribution. Regarding human capital accumulation, the rejection of distributional equality is less clear since we only reject the null at the $10 \%$ significance level. However, when we combine the effect of any two of the four components except for efficiency change, we find that the resulting counterfactual distribution is not significantly different from the actual 2003 distribution. Interestingly, when we introduce the effect of efficiency changes, we are again able to reject the null of equality in the distributions, since that factor dramatically shifts the counterfactual distribution towards the base period distribution. Not surprisingly, we also reject the null of distributional equality when we introduce the joint effect of TECH, KACC and HACC, as there would be clearly overshooting. This indirectly reflects the fact that, if it had not been for the large efficiency losses, the base period distribution would have shifted to the right much more over the 24-year period investigated.

\section{[Insert Table 3 about here]}

\subsection{Splitting the Sample Period}

Now it is interesting to investigate whether there is one particular subperiod driving the results for the whole period. An illustrative way to shed some light on this issue is to plot output per efficiency unit of labor against physical capital per efficiency unit of labor for each of the 17 regions. This allows us to determine whether there is a specific year from which regions began producing significantly less output with the same amount of inputs. This may be caused by a fall in efficiency or a reduction in the contribution of technological change to labor productivity growth. Given that most of the regions exhibit a fall in $\hat{y}$ relative to $\hat{k}$ in 1995 or adjacent year, we choose to split the sample period into two subperiods: $1980-1994$ and $1995-2003 .{ }^{16}$

Remarkably, the period 1980-1994 -with positive labor productivity growth combined with efficiency losses and positive contributions from technological change, capital deepening and human capital accumulation- appears to predominantly drive the outcome for the whole period. In contrast, the last subperiod represents a lost decade in terms of labor productivity growth, which 
has slightly regressed. This has been primarily caused by efficiency losses, zero technological change and extremely low contribution from capital deepening. ${ }^{17}$

The fact that these patterns are widespread across all regions points to the existence of common causes behind this dismal performance over the second subperiod. This may not only include macroeconomic factors induced by the state of the cycle ${ }^{18}$ or by wrong policies, but also country-wide unbalanced growth due to sectoral shifts towards those sectors with low or even negative productivity growth and to regional specialization in poorly performing sectors. In order to investigate these possibilities, in the rest of the article we move to a sector-level analysis.

\section{Sectoral Analysis}

Having explored the sources of aggregate labor productivity growth and convergence across the Spanish regions during the period 1980-2003, we now shift the focus to investigate whether individual sectors and/or the changing mix of industries are responsible for the economic performance of the aggregate private productive sector. Towards this end, we calculate efficiency scores as well as the quadripartite decomposition of labor productivity growth in the 17 regions for each sector. For the sake of saving space, we report the population-weighted average outcomes of such exercises, leaving to the unpublished appendix the detailed results for each region. ${ }^{19}$

Table 4 presents the results for the different sectors for the full period and both subperiods in a concise way. Remarkably, we observe that output per worker in agriculture, energy and manufacturing has on average grown much faster than total industry (private productive economy), with average changes over the 24 -year period equal to $197.5 \%, 117.6 \%$ and $63.5 \%$, respectively. Hence, the agricultural sector has exhibited a sixfold increase in labor productivity relative to the growth in total industry; the energy sector has more than tripled aggregate productivity growth and manufacturing has almost doubled it. In stark contrast stand the results for the construction and services sectors, whose labor productivity has hardly changed over the 24-year period (only $3 \%$ and $4.2 \%$, respectively). The marked sectoral differences in labor productivity underline the role of intra-sectoral productivity dynamics and possibly structural change in explaining aggregate productivity performance. Indeed, unbalanced growth patterns observed for individual regions as given by significant sectoral shifts from rapidly growing sectors such as agriculture and manufacturing to less productive ones (in terms of productivity growth) like the services and construction sectors are likely to bring about a fall in aggregate productivity change. ${ }^{20}$ We will come to this point in subsection 5.2 below.

Regarding the contribution attributable to each of the four components for each sector, we find the following: 
Agriculture: The extraordinarily high labor productivity growth has been mainly driven by rapid technological change (with a contribution of $96.6 \%$ ), followed by capital deepening that contributed by $38 \%$ and human capital accumulation by $18.3 \%$. Efficiency losses in this sector have been relatively low (-5\%). Still, out of the three regions (Cantabria, Castilla-la-Mancha and Navarra) located on the production frontier in 1980, only Castilla-la-Mancha retained a unit efficiency score in 2003. In this sector, convergence in labor productivity appears to be driven by technological change and capital deepening.

Manufacturing: The main contributor to productivity growth has been human capital accumulation $(21,3 \%)$, followed by technological change (18.7\%), capital deepening $(12.4 \%)$ and efficiency gains (2.4\%). In 1980, Rioja was the most efficient economy with a unit efficiency score, while Madrid the most efficient one in 2003. This sector does not show evidence of convergence in labor productivity. This is because the driving forces towards convergence stemming from physical capital deepening have been cancelled out by those causing divergence, as occurs with technological change and human capital accumulation.

Construction: The poor productivity growth performance is mainly driven by the very high efficiency losses that inhibited growth by $31.5 \%$. Hence, efficiency changes almost offset the positive contribution from technological change (22.6\%), human capital accumulation (13.7\%) and capital deepening (8.4\%). The dramatic fall in efficiency has been widespread in all the regions. From a situation in 1980 of three regions (Navarra, Rioja and Valencian Community) with an efficiency index of unity, we end up with a situation in which the highest efficiency index takes on a value of 0.66 for Asturias. In this sector, convergence in labor productivity is brought about by 1) efficiency changes as given by higher losses in rich regions relative to poor ones, and 2 ) the neoclassical mechanism associated with diminishing returns exhibited by physical capital accumulation.

Energy: The good growth performance can be attributed to technological change (45\%), followed by human capital accumulation (27\%), capital deepening (13\%) and efficiency gains (7.4\%). The frontier economy in 2003 is the Basque Country, while Canary Islands, Murcia and Rioja in 1980, with efficiency levels that fell dramatically during the 24-year period. Convergence in output per worker in this sector is entirely driven by the higher efficiency losses on the part of rich regions relative to lower losses in poor ones.

Services: The stagnation of this sector in terms of labor productivity change is caused by the extraordinarily high efficiency losses $(-47.6 \%)$, which almost offset the positive contributions from capital deepening (54\%), human capital accumulation (18.6\%) and technological change (9.4\%). Interestingly, efficiency losses have been higher and the contribution of technological change lower than in the other sectors. Given the high share that this sector has in the Spanish economy, this has constituted an important obstacle to labor productivity growth in the private productive sector. In this sector, efficiency losses have been particularly substantial, with most regions seeing their efficiency levels halved or even further reduced. In fact, the highest effi- 
ciency score reached by two regions (Cantabria and Valencia) equals 0.54 in 2003, which sharply contrasts with their unit efficiency indices in 1980. In this sector, convergence in labor productivity is driven by physical capital accumulation, which counteracts the statistically significant divergence-promoting effect of technological change. ${ }^{21}$

\section{[Insert Table 4 about here]}

Overall, the disparity of outcomes across sectors suggests that sectoral composition plays a relevant role in generating growth and convergence in aggregate labor productivity.

\subsection{Analysis of Subperiods: 1980-1994 and 1995-2003}

Remarkably, as occurred with total industry, the dynamics of the four components during the first subperiod appear to drive labor productivity growth for the whole period. In addition, labor productivity growth appears significantly reduced in the second subperiod relative to the first one, reaching even a negative value in construction and services. We also find that the contribution attributable to technological progress during the second subperiod is much lower than that of the first subperiod in each of the five sectors. In fact, as with total industry, technological change contributes zero to productivity growth in construction and services, and almost zero in energy. Interesting also is the small contribution of capital deepening during the second subperiod relative to the first one, which is close to zero in agriculture and energy, and even negative in manufacturing and construction. Though lower than in the first subperiod, the contribution of capital deepening in services is still significant (15\%), thus partly counteracting the effect of efficiency losses which amounts to $-21.4 \%$ during the $1995-2003$ subperiod.

The contribution of human capital is also considerably lower during the second subperiod in all sectors. Finally, unlike the three other components, we do not find a clear-cut pattern for efficiency changes. On the one hand, there is a worsening in efficiency in manufacturing and construction during the second subperiod. On the other, there is evidence of a clear improvement in efficiency in agriculture and energy that exhibit positive changes $(24.2 \%$ and $17.7 \%)$ relative to the negative variations during the first subperiod. Likewise, in services the negative contribution of efficiency changes has decreased from $-31.4 \%$ to $-21.4 \%$.

\subsection{Intrasectoral Dynamics or Sectoral Shifts?}

Unbalanced growth driven by rising shares in employment and output in construction and services, which are sectors with negative productivity change over the second subperiod, at the expense of falling shares in sectors with positive productivity growth like agriculture and manufacturing may be partly responsible for the negative productivity growth records observed over the period 1995-2003 in the aggregate private productive sector. In fact, as drawn in Figure 7, we 
observe that the share of employment in agriculture and manufacturing has steadily decreased at the expense of rising shares in construction and services. ${ }^{22}$ In addition, regional specialization in sectors with low productivity growth (which turns negative over the second subperiod) may also explain such dismal productivity growth performance.

\section{[Insert Figure 7 about here]}

Hence, we now try to determine the contribution to labor productivity growth in total industry atributable to (1) instrasectoral productivity growth due to a specific configuration of regional specialization and (2) structural change caused by sectoral shifts. To formalize this intuition, we follow EsTEBAN (2000) by employing the following expression:

$$
\begin{aligned}
\left(\frac{\frac{G V A_{c}}{L_{c}}-\frac{G V A_{b}}{L_{b}}}{\frac{G V A_{b}}{L_{b}}}\right)= & \frac{\sum_{j=1}^{5} \frac{L_{j b}}{L_{b}}\left(\frac{G V A_{j c}}{L_{j c}}-\frac{G V A_{j b}}{L_{j b}}\right)}{\frac{G V A_{b}}{L_{b}}}+\frac{\sum_{j=1}^{5} \frac{G V A_{j b}}{L_{j b}}\left(\frac{L_{j c}}{L_{c}}-\frac{L_{j b}}{L_{b}}\right)}{\frac{G V A_{b}}{L_{b}}}+ \\
& +\frac{\sum_{j=1}^{5}\left(\frac{L_{j c}}{L_{c}}-\frac{L_{j b}}{L_{b}}\right)\left(\frac{G V A_{j c}}{L_{j c}}-\frac{G V A_{j b}}{L_{j b}}\right)}{\frac{G V A_{b}}{L_{b}}}
\end{aligned}
$$

where $j$ refers to each of the five sectors, and $b$ and $c$ stand for base (1980) and current (2003) period, respectively. The first component is the intrasectoral productivity growth effect $(P G E)$ which constitutes the percentage contribution to aggregate productivity growth for each region or Spain (depending on the case) of within sector productivity growth, using initial sectoral employment shares as weights (i.e. assuming that the sectoral employment structure remains unchanged over the 24-year-period). The second component called the static share effect $(S E)$ shows the percentage contribution of shifting sectoral composition to aggregate labor productivity growth, considering that sectoral productivity does not change (i.e. assuming that initial levels of sectoral productivity remain unaltered). Those sectors with falling employment shares will exhibit negative share effects. The third component called the interaction dynamic effect $(D E)$ shows the percentage contribution of the interaction between the variations in the sectoral share of employment and labor productivity to aggregate productivity growth.

Panel A of Table 5 reports the three effects for each of the regions as well as for Spain as a whole over the full period. The results of this shift-share analysis indicate that sectoral contributions to aggregate productivity growth for all the regions and Spain are predominantly driven by within sector effects. ${ }^{23}$ Indeed, if one compares the intrasectoral productivity growth effect to the total effect, we observe that they are almost equal for most regions and Spain, the only exception being the Balearic Islands. In contrast, we find overall limited contribution stemming from sectoral shifts from high-productivity sectors gaining employment shares or lowproductivity sectors losing shares, since the positive static share effect is practically cancelled out by the negative dynamic effect in all regions (but the Balearic Islands) and the whole Spain. ${ }^{24}$ There are regions (Castilla-la-Mancha, Catalonia, Extremadura, Madrid, Navarra, the Basque Country and Rioja) where the dynamic effect is even higher in absolute terms than the share 
effect. Overall, we can infer that aggregate labor productivity dynamics are primarily driven by intrasectoral productivity dynamics rather than by shifting sectoral composition, as shown in the percentage contribution of the productivity growth effect.

Regarding the analysis by subperiods shown in Panels B and C of Table 5, the evidence for the subperiod 1980-1994 appears in line with those for the full period, with a percentage contribution of the within-sector productivity growth effect relative to that of the static share effect of about three to one for most regions and Spain. Again, the Balearic Islands behave differently from the rest, but in this case the intrasectoral productivity growth effect is positive due to the fact that the largest losses in labor productivity growth in services ocurred during 1995-2003. The results for the second subperiod are marked by productivity losses in most of the regions (as captured by the total effect), the exceptions being Asturias, Castilla-Leon, Valencian Community, Extremadura and Galicia. In these five regions, there are large enough positive intrasectoral productivity growth effects that counteract the overall negative effect from sectoral shifts towards sectors with low productivity, particularly construction and services.

In all, this shift-share analysis provides consistent evidence that the bulk of aggregate productivity growth is driven by intrasectoral productivity growth dynamics rather than structural change.

[Insert Table 5 about here]

\section{Discussion of our Results in Light of Previous Findings}

At this point it is important to compare our main findings with those obtained by MAUDOS et al. (2000b) and SALINAS JimÉnez (2003a) and SAlinas JimÉnez (2003b). Even though MAUDOs et al. (2000b) focus on the effect of efficiency changes on convergence of labor productivity rather than on the sources of productivity growth, their analysis supports our finding of efficiency changes acting as a main engine of convergence. In addition, they find evidence of a reduction in inefficiency between 1964 and 1993 in agriculture, manufacturing and construction, while not much change in efficiency for energy and services. Though not directly comparable, as we are focusing on a different and more recent period (1980-2003) with an alternative dataset, we also find evidence of efficiency improvements in agriculture across both subperiods (1980-1994 relative to 1995-2003). However, the results for the other sectors differ across studies, since we find evidence of efficiency decreases across subperiods for manufacturing, while efficiency improvements in energy and lower efficiency losses in services. The pattern of significant efficiency losses for construction remains fairly constant across subperiods.

In addition, given the differences in the time period 1965-1995 analyzed and in the dataset employed by SALINAS JimÉNEZ (2003b) relative to our study -in addition to focusing more on the aggregate rather than on regions-, we do not expect to obtain strictly similar results in 
both studies. And more so when SALINAS JIMÉNEZ (2003b) failed to include human capital in her labor productivity decomposition. In fact, SALINAS JimÉneZ (2003b) finds positive productivity contributions from efficiency change, while we find widespread evidence of efficiency losses in the whole Spain as well as in all regions but Extremadura. This is likely to stem from the fact that SALINAS JimÉnEZ (2003b) does not include human capital accumulation as a component of productivity change, which in our analysis appears to be the second main driver of productivity change, with a contribution of about $20 \%$, very close to the $22 \%$ contribution attributable to physical capital accumulation. This indicates that failure to incorporate human capital measures into the productivity change decomposition makes efficiency changes capture the positive influence of human capital accumulation. This results in a positive productivity contribution from efficiency changes, while our results clearly point to widespread efficiency losses across the Spanish regions.

SALINAS JimÉnEZ (2003a) decomposes TFP growth into technological progress and efficiency changes by means of a Malmquist index. Instead of including human capital accumulation directly in the decomposition of labor productivity growth, she estimates panel data regressions of efficiency changes as a function of human capital. Her results lend support to our previous discussion, since they point to the significantly positive effect of human capital accumulation on efficiency gains through the catch-up process. Hence, failure to include human capital accumulation in the decomposition will result in an upwardly biased contribution of efficiency changes, as occurs in SALINAS JIMÉNEZ (2003b).

\section{Conclusion}

This paper represents the first known analysis of the sources of growth and convergence across two dimensions (regional and sectoral) jointly employing a nonparametric production frontier approach and distribution dynamics methods. The advantages of this frontier approach over standard regression-based growth accounting exercises are that (1) it neither requires specification of any particular production function technology nor the existence of perfectly competitive markets or Hicks-neutral technological change, (2) it allows us to distinguish between catching-up (movements towards the frontier) and technological change (shifts in the frontier), (3) it allows for the modelling of inefficiency of regional economies and sectors. The quadripartite decomposition enables us to decompose labor productivity growth into four components attributable to technological catching-up, technological change, capital deepening and human capital accumulation. This together with the examination of the evolution of the entire cross-section distribution and the degree to which the four components of productivity change accounts for such productivity dynamics enable us to determine the specific role of each of the components in growth and convergence. 
Our main results for aggregate productivity indicate that (1) technological change is clearly nonneutral in Hicks sense, (2) capital deepening is the primary contributor to aggregate labor productivity growth, closely followed by human capital accumulation and technological change; (3) widespread efficiency losses appear to substantially inhibit productivity growth; (4) simple convergence regressions as well as the analysis of the cross-region distribution of labor productivity in terms of the quadripartite decomposition support the existence of convergence in labor productivity, mainly driven by the higher efficiency losses exhibited by rich regions relative to poor ones. In addition, the sectoral analysis evinces (5) marked differences in productivity performance as well as in the contribution of the four components across sectors; (6) aggregate productivity growth is mainly driven by intrasectoral productivity dynamics -primarily in manufacturing and agriculture- rather than structural change; (7) for both total industry and the five sectors separately, productivity dynamics during the subperiod 1980-1994 appear to predominantly drive the outcome for the whole period. Overall, this analysis underlines the fact that the subperiod 1995-2003 constitutes a lost decade in terms of labor productivity that has slightly regressed due to efficiency losses, zero technological change and very low contribution from capital deepening.

The analysis of data with such a high degree of detail (regional, sectoral and over time) has helped us identify the exact sources of the poor labor productivity performance in Spain. Remarkably, efficiency losses appear widespread across regions and in three sectors (agriculture, construction and services) for the whole period, with manufacturing also exhibiting efficiency losses during the last subperiod. In addition, the fact that the source of the reduction in disparities across regions is the higher efficiency losses incurred by rich regions relative to lower losses in poor ones appears highly disappointing. Hence, this indicates that rather than converging toward the technological frontier, regional economies are moving away from the frontier. This is particularly the case for rich regions that, over the 24-year-period analyzed, have seen their efficiency scores going down to comparable levels to those characteristic of poor regions. If we add to this the fact that over the period 1995-2003 the contribution attributable to technological change has come to a halt and that of capital deepening has been negligible, we can be nothing but very pessimistic about the prospects that the Spanish economy faces for the coming years.

To reverse this situation, policymakers should make the effort to conduct structural reforms with the aim of bringing efficiency gains by helping regional economies move towards the bestpractice frontier. Hence, Spanish regions could boost their growth if they manage to reverse the negative trends in efficiency observed over the whole period. The current crisis should be seen as an opportunity to wipe out the most inefficient firms in the least efficient sectors (particularly construction) and then reallocate resources to the best performing sectors (agriculture, manufacturing and energy). In addition, productivity growth gains can be reaped by promoting capital accumulation and especially technological change, whose contribution has been extremely low or zero over the subperiod 1995-2003. 


\section{Notes}

${ }^{1}$ Throughout the text, we will interchangeably use labor productivity and productivity.

${ }^{2}$ Subsequent models like those of Romer (1990) and Grossman and HelPMan (1991) have attempted to endogenize technological progress by making it directly depend on the resources devoted to innovating through research and development (R\&D). Other theoretical models like NELSON and PhelPS (1966), BARRO and SALA-I MARTín (1997) and empirical models like BenHABIB and SPIEGEL (1994) have emphasized the role of technology diffusion helping lagging economies to catch up to the productivity levels of the best-practice frontier economy, as the main source of growth and convergence over extended periods of time. More recently, LEÓN-LEDESMA (2002) develops an extended version of the canonical Kaldorian cumulative growth model, which is characterized not only by forces leading to income divergence (such as technological innovation through learning and non-price competitiveness) but also by factors inducing income convergence (such as the diffusion of technologies arising from the productivity gap with respect to the leading economy).

3 KuMAR and RUSSELL (2002), in their concluding section, also called for a more disaggregated analysis of convergence and growth sources.

${ }^{4}$ Remarkably, failure to include human capital measures in the productivity change decomposition leads efficiency changes to contribute positively to productivity change. In contrast, incorporating human capital proxies in our decomposition provides clear-cut evidence of widespread efficiency losses and a significantly positive contribution from human capital accumulation for most of the regions and the aggregate.

${ }^{5}$ The authors would like to thank María José Murgui for making readily available this dataset.

${ }^{6}$ According to DABÁN et al. (2002), the net stock of private productive physical capital provided by the BD.MORES.2000 dataset appears more in line (than several alternative physical capital stock estimates for the Spanish economy) with the estimates in international databases like the Business Sector Database (OECD).

${ }^{7}$ For the sake of data consistency and accuracy, we prefer to use this dataset until 2003 than adding two or three more years using alternative data sources. In addition, we centre our analysis on the 17 regions rather than on 51 provinces, which is the spatial dissagregation level provided by the BD.MORES.2000.

${ }^{8}$ Further details on methodology development can be found in the original article of HENDERSON and RUSSELL $(2005)$.

MCCOMBIE and RoBerTs (2007) note that the empirical literature does not provide unambiguous evidence whether returns to scale are constant or increasing when referring to regional data. SALINAS JiMÉNEZ (2003b), for example, assumes constant returns to scale in an analysis of Spanish regional data. We perform the statistical test of SIMAR and WILSON (2002) to test the underlying technology. Using the data for 1980 and 2003 we cannot 
reject the null hypothesis that the global technology is constant returns to scale ( $p$-values are 0.3596 and 0.3262 ) in these years.

${ }^{10}$ This fact only tells us that Extremadura's relative distance to the frontier did not change.

${ }^{11}$ In order to see this, if we apply such formula to the first row of Table 2 , we obtain: $1.339=0.830 \times 1.162 \times$ $1.130 \times 1.228$.

${ }^{12}$ It is remarkable that two highly populated regions like Madrid and the Valencian Community exhibit high relative contribution of physical capital accumulation but low contribution attributable to technological change and human capital accumulation. In contrast, in most of the regions with relatively low population like Aragon, the Balearic Islands, Cantabria, Extremadura, Navarra, Rioja and to a less extent the Basque Country, the contribution of physical capital is much lower than that attributable to technological change and human capital. These patterns lead the weighted average contribution of capital deepening to be higher than the unweighted one, occurring exactly the opposite for technological change and human capital accumulation.

${ }^{13}$ For the sake of robustness, we have also redone this quadripartite decomposition in each region for total industry using: (1) a series labelled as 'human-capital equivalent' which measures the human capital of a worker as a function of the number of 'zero-skill workers' (with no education or experience) that would be necessary to attain the worker's productive capacity, measured by accumulated experience and education; and (2) an alternative measure of human capital provided by DE LA FUENTE and DOMÉNECH (2006) as given by the average years of schooling in the working-age population over 25 based on census data. Remarkably, our main results remain unaltered when we employ these alternative human capital measures. These unreported results can be accessed in the unpublished appendix made available in the authors' homepage.

${ }^{14}$ To add a word of caution, we conduct this simple exercise just to have a preliminary idea of the sources of convergence. A more detailed distributional analysis to investigate convergence dynamics is presented below.

${ }^{15}$ If $f$ and $g$ are these distributions, this statistic tests the null hypothesis $H_{0}: f(x)=g(x)$ for all $x$, against the alternative $H_{1}: f(x) \neq g(x)$ for some $x$. See the (unpublished) methodological appendix for a more detailed account of the construction of this test.

${ }^{16}$ Due to space limitations, these scatterplots as well as the detailed description of the results are not reported, but they are available in the unpublished appendix.

${ }^{17}$ To conserve space, we do not report the production frontiers, the quadripartite decomposition results, the convergence scatterplots and the distributional analysis for both subperiods. However, these results are readily available in the unpublished appendix.

${ }^{18}$ However, we may discard cyclical factors since the Spanish economy over the period 1995-2003 experienced a long expansion. 
${ }^{19}$ The appendix also contains the production frontier plots, the convergence scatterplots and the distributional analysis for each sector and the quadripartite decomposition for individual regions within each sector.

${ }^{20}$ It is important to note that the construction sector has experienced an incredible boom over this 24-year period, changing from 1,173.5 to 2,335.2 thousand employees. Likewise, GVA has doubled over the 1980-2003 period (from 28,323 to 57,642 million euros).

${ }^{21}$ The results from simple convergence regressions reported in this section largely coincide with the evidence from (unreported) figures of $\sigma$-convergence plotting the standard deviation of the log of output per worker for the aggregate and the five sectors separately. Besides finding a decrease in dispersion in aggregate productivity, there is also a large fall in dispersion in labor productivity differences across regions in agriculture, a moderate fall in regional disparities in energy, slight inequality reductions in services and construction, while a slight increase in interregional productivity disparities in manufacturing. These figures are available in the unpublished appendix.

${ }^{22}$ Exactly the same sectoral shifting patterns are observed for every single region. Again, due to space limitations these unreported plots are available in the unpublished appendix.

${ }^{23}$ For the whole Spain, the productivity growth effect in percentage terms for agriculture, manufacturing, construction, energy and services is $35.5,43,0.7,12.8$ and $8 \%$, respectively. Hence, manufacturing followed by agriculture are the sectors driving aggregate productivity growth. Interesting also is the finding of negative static share effects (in percentage terms) for agriculture (-24.93), manufacturing (-39.23) and energy (-15.63). This fully accords with Figure 7 that shows falling employment shares for agriculture and manufacturing and to a much less extent for energy.

${ }^{24}$ The case of the Balearic Islands is special in terms of a configuration based on a very marked specialization in services. This sector has gained a lot of weight over the 24-year period considered (moving from about 50 to almost 70\%), but at the expense of large labor productivity losses (GVA per worker falling from 49391.4 to 37890.7 between 1980 and 2003). The productivity losses in services are so large that lead to a negative productivity growth effect, thus counteracting the positive intrasectoral productivity growth effects from manufacturing and energy. In addition, the static share effect appears large and positive due to the sectoral shifts from agriculture and manufacturing to services. However, once we also take into account the loss in productivity brought about by sectoral shifts, we find a large negative dynamic effect that counteracts to a great extent the positive effect from the static share effect. 


\section{References}

Barro R. and SAla-I Martín X. (1997) Technological diffusion, convergence, and growth, Journal of Economic Growth 2(1), 1-26.

Benhabib J. and Spiegel M. M. (1994) The role of human capital in economic development: Evidence from aggregate cross-country data, Journal of Monetary Economics 34(2), 143-173.

Bernard A. B. and Jones C. I. (1996a) Comparing apples to oranges: Productivity convergence and measurement across industries and countries, American Economic Review 86(5), $1216-1238$.

Bernard A. B. and Jones C. I. (1996b) Productivity across industries and countries: Time series theory and evidence, The Review of Economics and Statistics 78(1), 135-146.

Bernard A. B. and Jones C. I. (1996c) Technology and convergence, Economic Journal 106(437), 1037-1044.

CAss D. (1965) Optimum growth in an aggregative model of capital accumulation, Review of Economic Studies 32, 233-240.

Dabán T., Díaz A., Escribá F. J. and Murgui M. J. (2002) La Base de Datos BD.MORES, Revista de Economía Aplicada X(30), 165-184.

de Bustos A., Cutanda A., Díaz A., Escribá F. J., Murgui M. J. and Sanz M. J. (2008) La BD.MORES en Base 2000: Nuevas Estimaciones y Variables, Ministerio de Econom'ia y Hacienda del Gobierno de España.

De la Fuente A. and Doménech R. (2006) Capital Humano y Crecimiento en las Regiones Españolas, Moneda y Crédito 222, 13-78.

DiEWERT W. E. (1980) Capital and the theory of productivity measurement, The American Economic Review 70(2), 260-267.

EscribÁ F. J. and Murgui M. J. (2001) Tecnología, Cambio Estructural y Convergencia en las Regiones Españolas (1980-1995), Investigaciones Económicas XXV(2), 335-357.

Esteban J. (2000) Regional convergence in Europe and the industry mix: A shift share analysis, Regional Science and Urban Economics 30, 353-364.

Färe R., Grosskopf S., Norris M. and Zhang Z. (1994) Productivity growth, technical progress, and efficiency change in industrialized countries, American Economic Review 84, $66-83$.

FARrell M. J. (1957) The measurement of productive efficiency, Journal of the Royal Statistical Society. Series A (General) 120(3), 253-290. 
Grossman G. N. and Helpman E. (1991) Innovation and Growth in the Global Economy, The MIT Press.

Hall R. E. and Jones C. I. (1999) Why do some countries produce so much more output per worker than others?, Quarterly Journal of Economics 114(1), 83-116.

Henderson D. J. and Russell R. R. (2005) Human capital and convergence: A productionfrontier approach, International Economic Review 46(4), 1167-1205.

Kumar S. and Russell R. R. (2002) Technological change, technological catch-up, and capital deepening: Relative contributions to growth and convergence, American Economic Review 92(3), 527-548.

Lamo A. (2000) On convergence empirics: Some evidence for spanish regions, Investigaciones Económicas 24(3), 681-707.

León-Ledesma M. A. (2002) Accumulation, innovation and catching-up: An extended cumulative growth model, Cambridge Journal of Economics 26, 201-216.

Li Q. (1996) Nonparametric testing of closeness between two unknown distribution functions, Econometric Reviews 15, 261-274.

LI Q. (1999) Nonparametric testing the similarity of two unknown density functions: Local power and bootstrap analysis, Journal of Nonparametric Statistics 11, 189-213.

LuCAS R. E. (1988) On the mechanics of economic development, Journal of Monetary Economics 22(1), 3-42.

Margaritis D., FÄre R. and Grosskopf S. (2007) Productivity, convergence and policy: A study of OECD countries and industries, Journal of Productivity Analysis 28(1), 87-105.

Maudos J., Pastor J. M. and Serrano L. (2000a) Convergence in OECD countries: Technical change, efficiency and productivity, Applied Economics 32, 757-765.

Maudos J., Pastor J. M. and Serrano L. (2000b) Efficiency and productive especialization: An application to the Spanish regions, Regional Studies 34(9), 829-842.

McCombie J. S. L. and Roberts M. (2007) Returns to scale and regional growth: the staticdynamic Verdoorn Law paradox revisited, Journal of Regional Science 47(2), 179-208.

Nelson R. R. and Phelps E. S. (1966) Investment in humans, technological diffusion, and economic growth, The American Economic Review 56(1/2), 69-75.

Psacharopoulos G. (1994) Returns to investment in education: A global update, World Development 22, 1325-1343. 
QuAH D. (1993) Galton's fallacy and tests of the convergence hypothesis, Scandinavian Journal of Economics 95(4), 427-443.

QUAH D. (1996) Twin peaks: Growth and convergence in models of distribution dynamics, Economic Journal 106(437), 1045-1055.

Romer P. (1986) Increasing returns and long-run growth, Journal of Political Economy 94(5), 1002-1037.

Romer P. (1990) Endogenous technological change, Journal of Political Economy 98(5), S71S102.

Salinas JimÉnez M. D. M. (2003a) Efficiency and TFP growth in the Spanish regions: The role of human and public capital, Growth and Change 34(2), 157-174.

Salinas JimÉnez M. D. M. (2003b) Technological change, efficiency gains and capital accumulation in labour productivity growth and convergence: an application to the Spanish regions, Applied Economics 35(17), 1839-1851.

Serrano L. and Soler A. (2008) Metodología para la Estimación de las Series de Capital Humano. 1964-200\%, Instituto Valenciano de Investigaciones Económicas and Bancaja.

Sheather S. J. and Jones M. C. (1991) A reliable data based bandwidth selection method for kernel density estimation, Journal of Royal Statistical Society, Series B 53, 683-990.

Simar L. and Wilson P. W. (2002) Non-parametric tests of returns to scale, European Journal of Operational Research 139, 115-132.

Solow R. (1956) A contribution to the theory of economic growth, Quarterly Journal of Economics 70, 65-94.

Summers R. and Heston A. (1991) Penn World Table Version. mark 5: An expanded set of international comparisons, 1950-1988, Quarterly Journal of Economics 206(2), 327-368.

Tortosa-Ausina E., Pérez F., Mas M. and Goerlich F. J. (2005) Growth and convergence profiles in the Spanish provinces, Journal of Regional Science 45(1), 147-182. 
Production Frontiers in 1980 and 2003

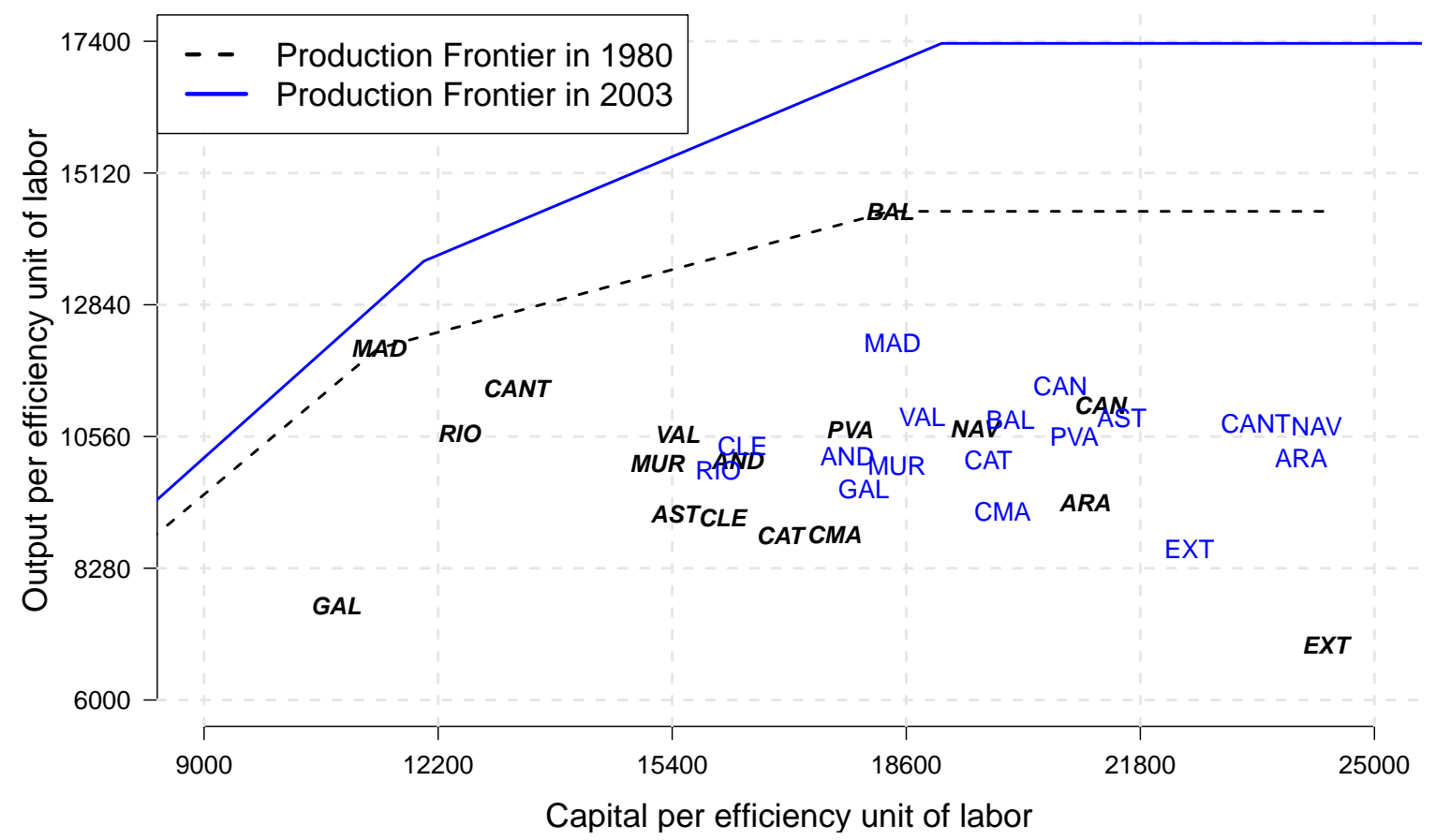

Notes: The bold italic abbreviations show the 1980 observations and the normal font abbreviations show the 2003 observations. The dotted line represents the 1980 production frontier and the solid line presents the 2003 production frontier.

Figure 1: Production frontiers in 1980 and 2003 
Distribution of Efficiency Index, 1980 and 2003

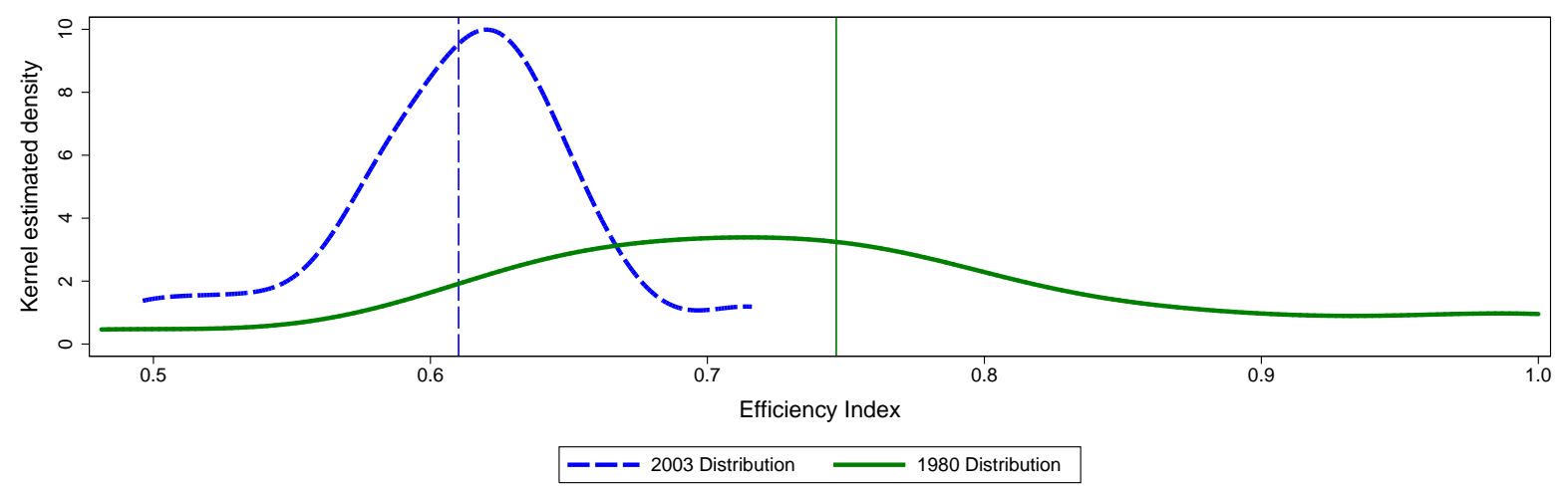

Notes: The solid vertical line represents mean of 1980 efficiency distribution and the the dashed curve is the mean of 2003 efficiency distribution.

Figure 2: Distributions of efficiency scores in 1980 and 2003 


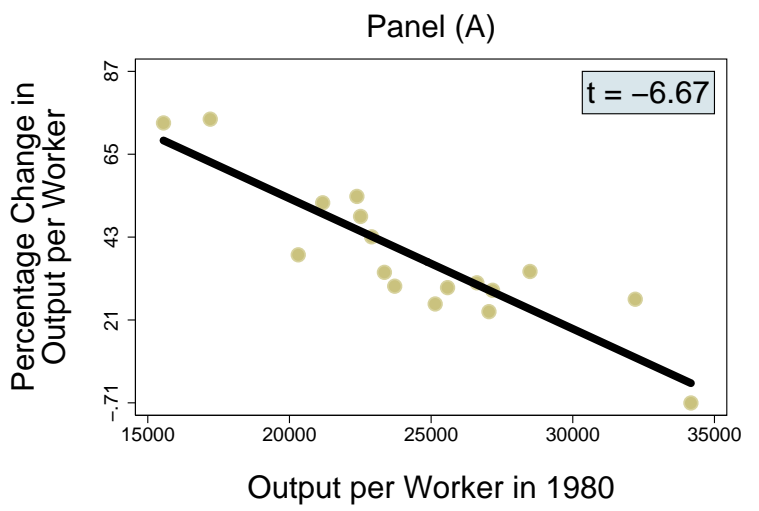

Panel (B)
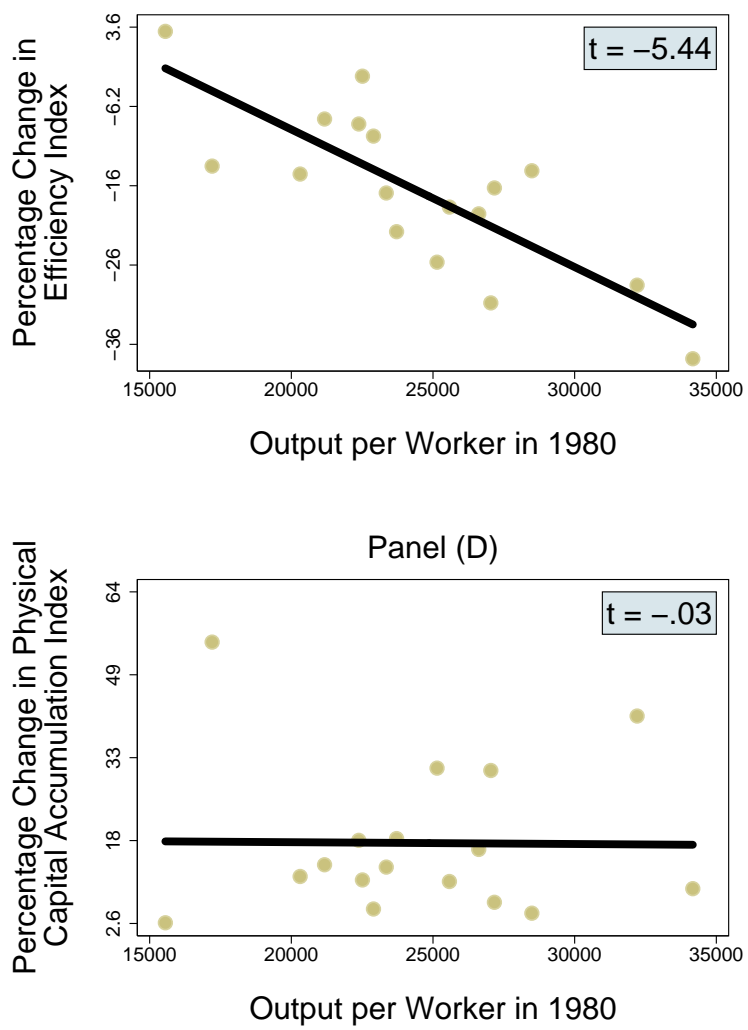

Panel (C)
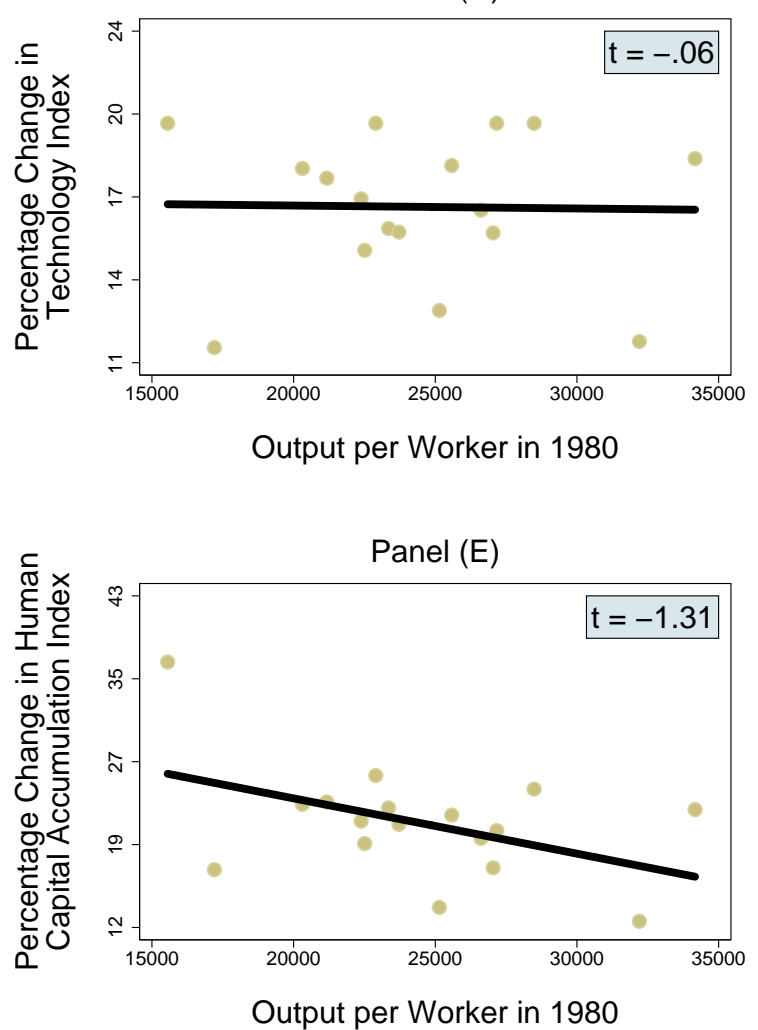

Note: Each panel contains a GLS regression line; the topright figure in each panel shows a $t$-statistic of a respective GLS regression.

Figure 3: Percentage change (from 1980 to 2003) in output per worker and four decomposition indexes, plotted against output per worker in 1980 
Figure 4: Actual Distributions of Output per Worker

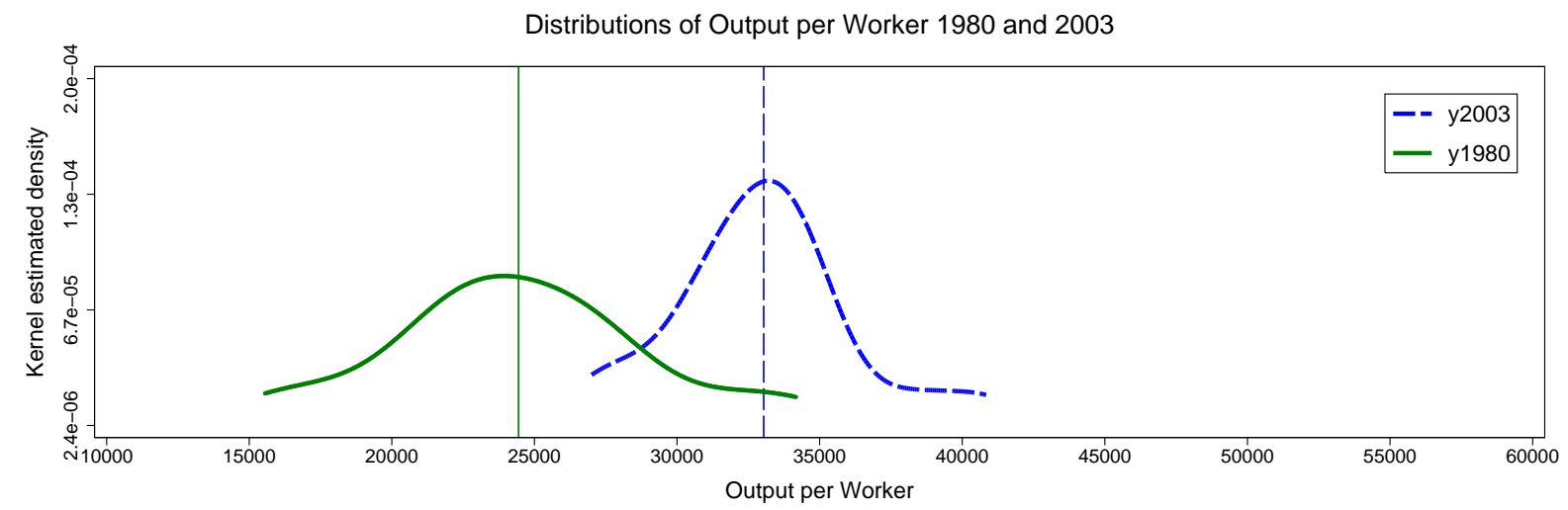

Notes: The solid curve is the actual 1980 distribution and the dashed curve is the actual 2003 distribution. 
(a) Effect of Capital Deepening

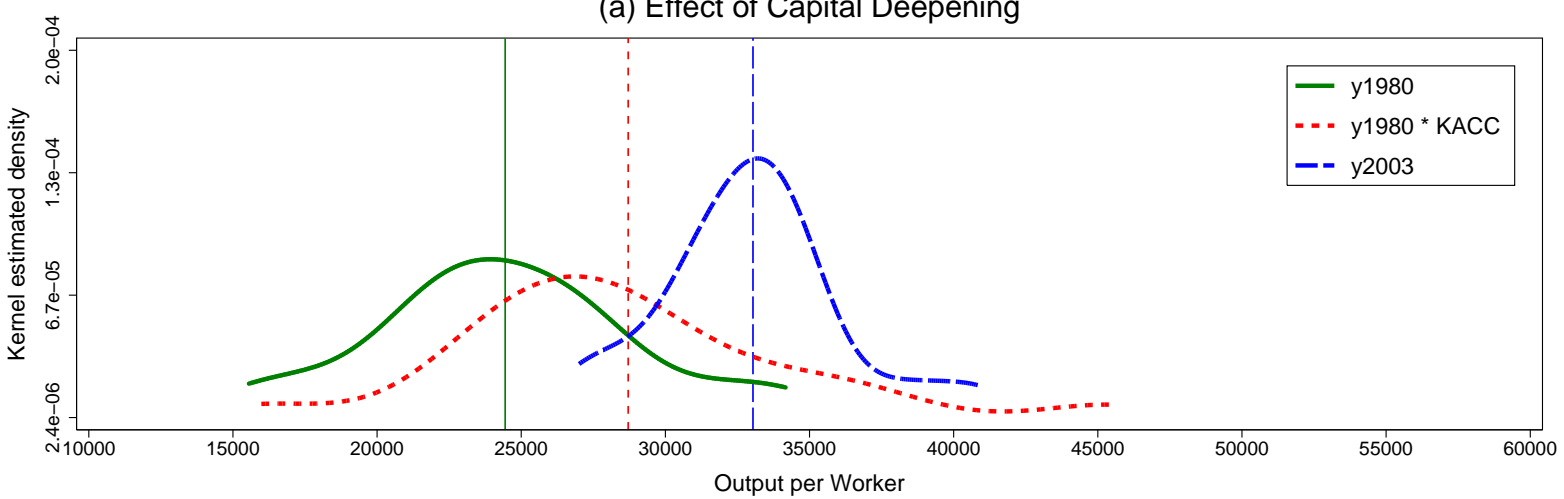

(b) Effect of Human Capital Accumulation

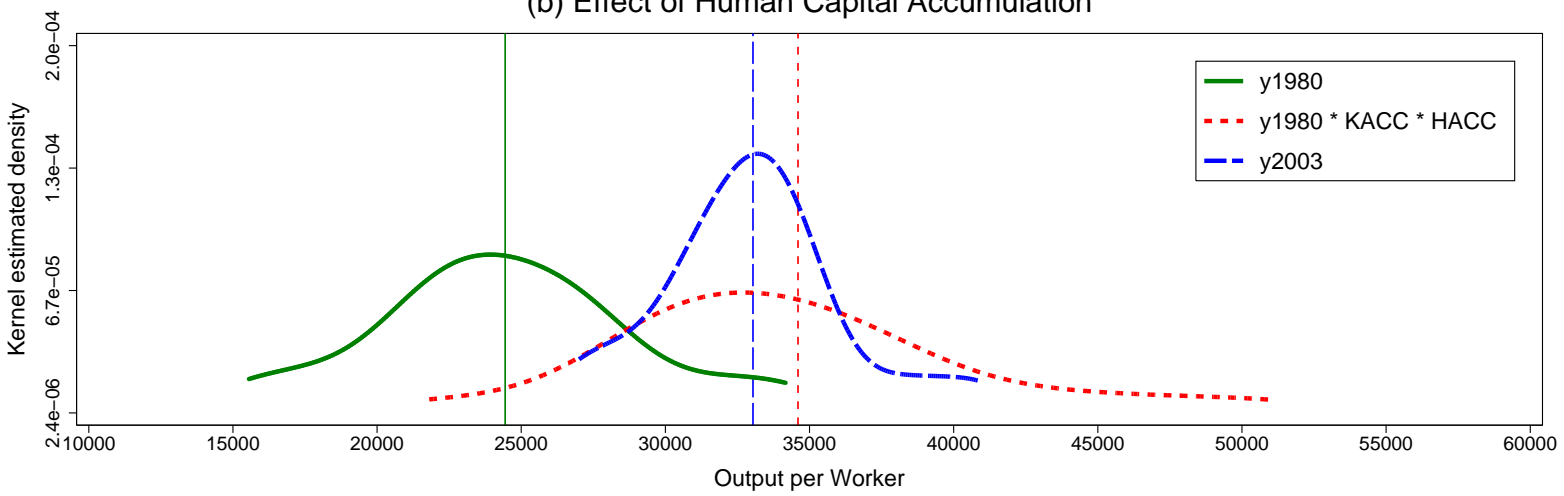

(c) Effect of Efficiency Change

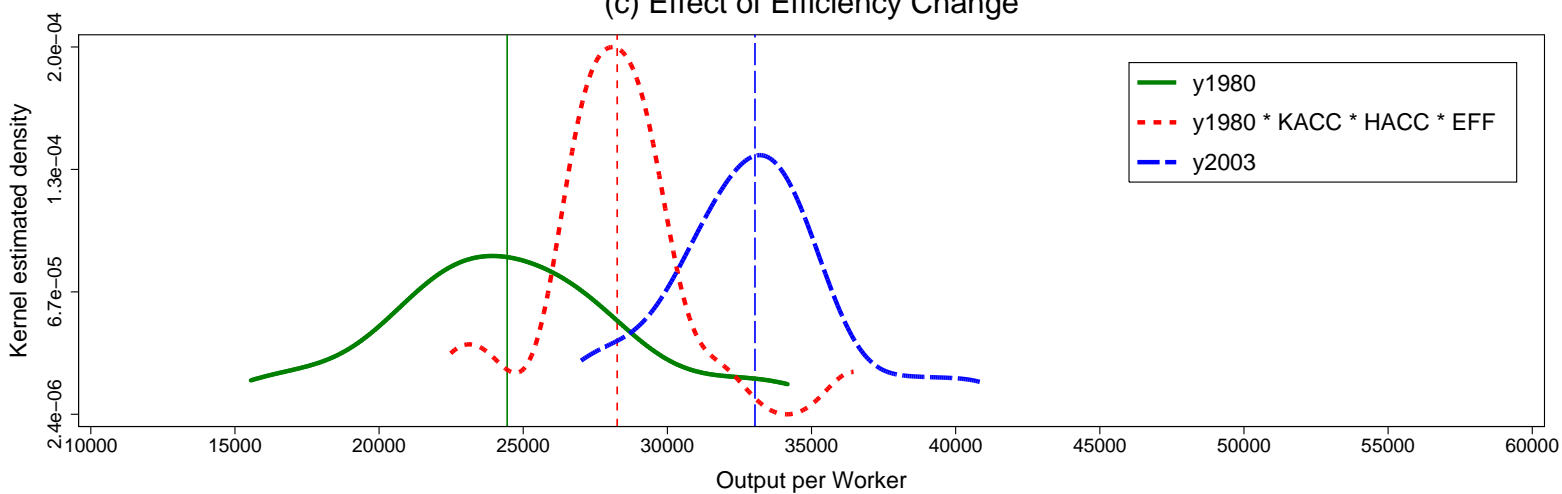

Notes: In each panel, the solid curve is the actual 1980 distribution and the dashed curve is the actual 2003 distribution. The dotted curves in each panel are the counterfactual distributions isolating, sequentially, the effects of capital deepening, human capital accumulation, and efficiency change on the 1980 distribution.

Figure 5: Counterfactual Distributions of Output per Worker. Sequence of introducing effects of decomposition: KACC, HACC, and EFF 


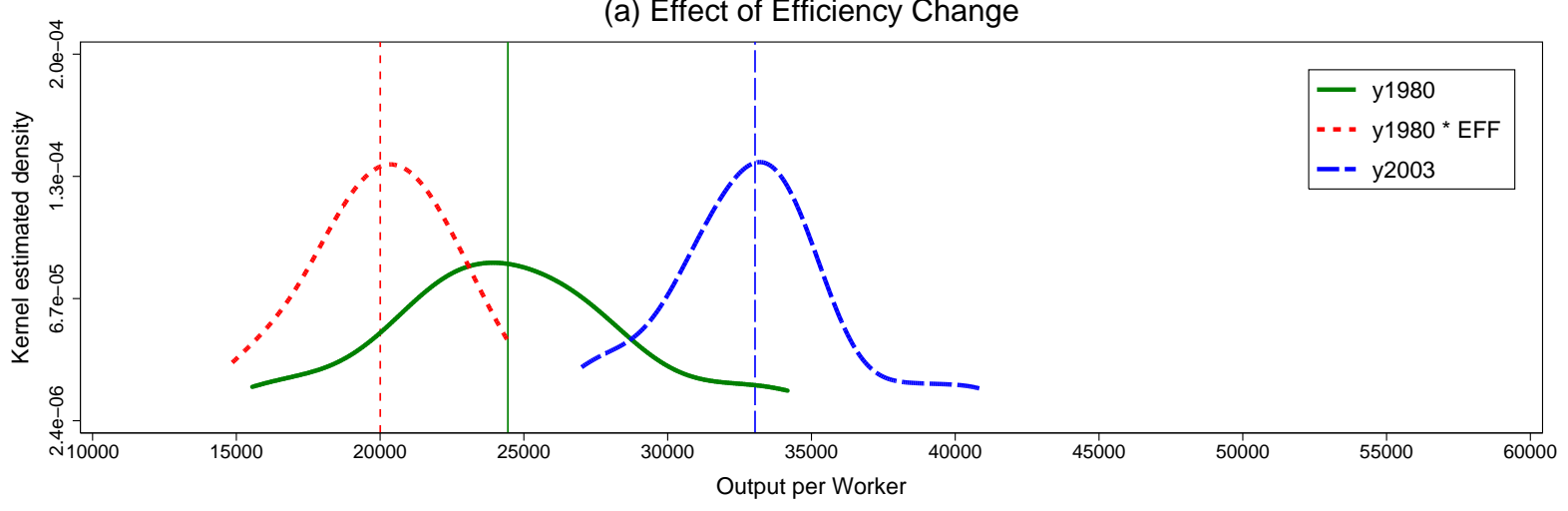

(b) Effect of Technological Change

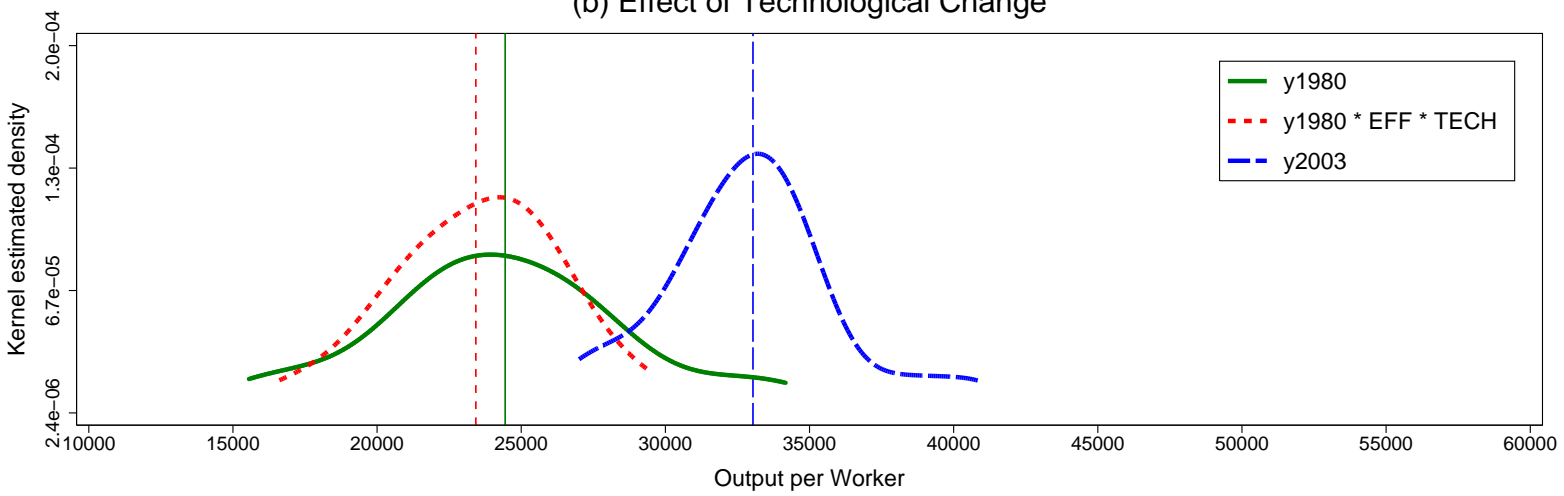

(c) Effect of Capital Deepening

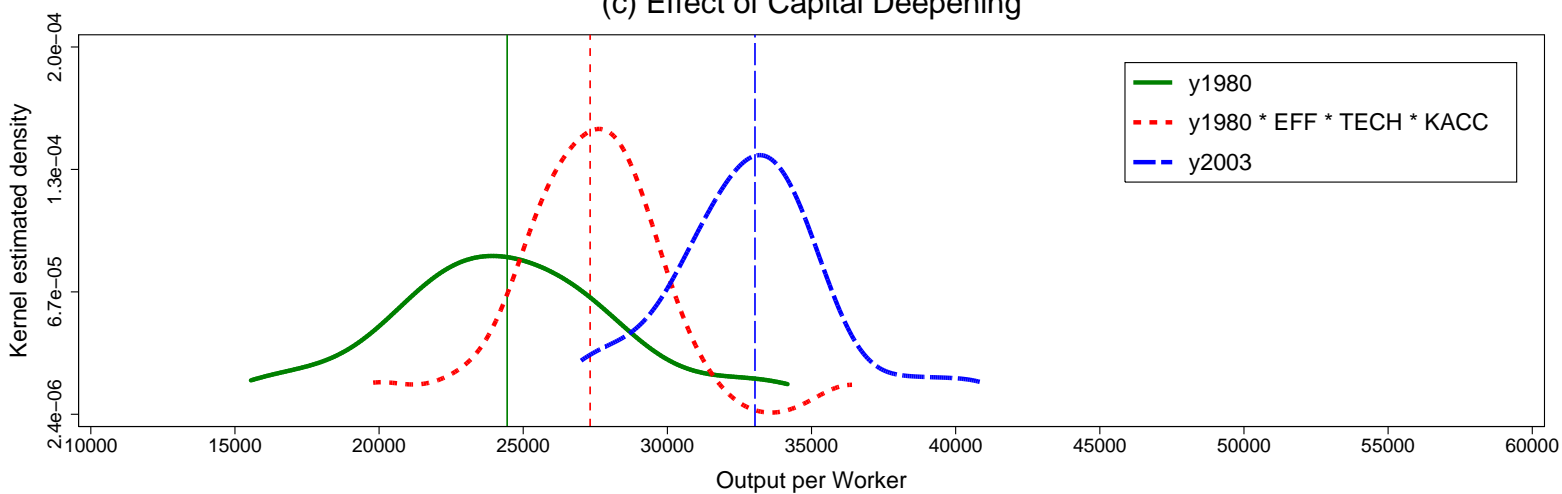

Notes: In each panel, the solid curve is the actual 1980 distribution and the dashed curve is the actual 2003 distribution. The dotted curves in each panel are the counterfactual distributions isolating, sequentially, the effects of efficiency change, technological change, and capital deepening on the 1980 distribution.

Figure 6: Counterfactual Distributions of Output per Worker. Sequence of introducing effects of decomposition: EFF, TECH, and KACC 


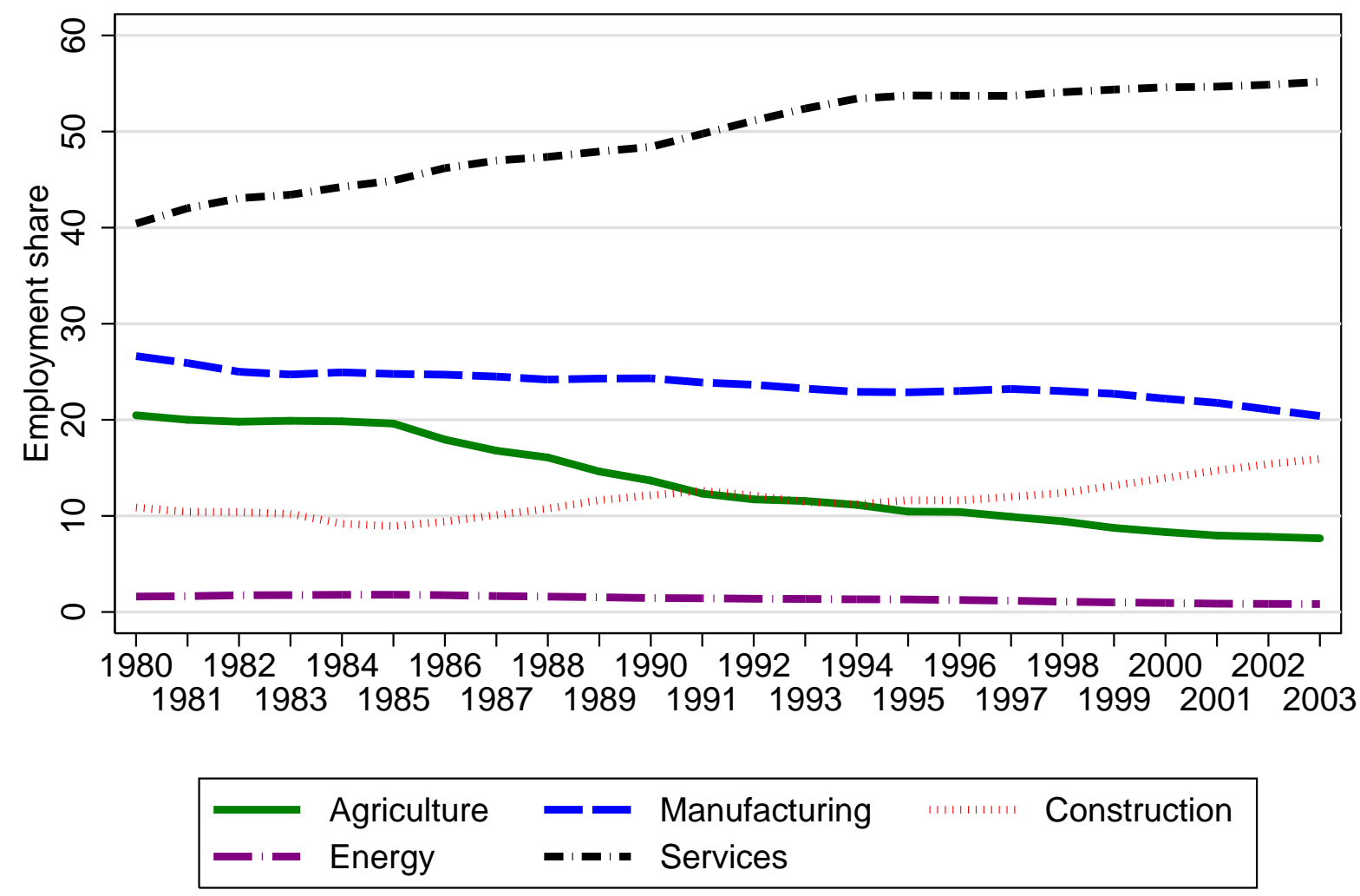

Figure 7: Evolution of Sectoral Employment Shares 
Table 1: Descriptive statistics, 1980-2003

\begin{tabular}{|c|c|c|c|c|c|}
\hline Region & Code & Mean & $\begin{array}{l}\text { Standard } \\
\text { deviation }\end{array}$ & Minimum & Maximum \\
\hline \multicolumn{6}{|c|}{ Gross Value Added at Factor Cost } \\
\hline Andalusia & AND & 45840059 & 9968081 & 32058486 & 65287664 \\
\hline Aragon & ARA & 11456107 & 2166707 & 8453551 & 15498520 \\
\hline Asturias & $\mathrm{AST}$ & 8859636 & 908495 & 7683989 & 10758029 \\
\hline Balearic Islands & BAL & 9057515 & 2029601 & 6058276 & 12282148 \\
\hline Basque Country & PVA & 23621367 & 3805047 & 18893504 & 31380374 \\
\hline Canary Islands & CAN & 14005874 & 2702194 & 10853846 & 19625305 \\
\hline Cantabria & CANT & 4581157 & 817538 & 3587946 & 6233290 \\
\hline Castilla-La Mancha & CMA & 12017629 & 2517868 & 8611453 & 16404440 \\
\hline Castilla-Leon & CLE & 20274042 & 3275145 & 15424098 & 26576683 \\
\hline Catalonia & CAT & 70229754 & 16308893 & 49775093 & 98908983 \\
\hline Extremadura & EXT & 5512689 & 1129005 & 3734001 & 7535355 \\
\hline Galicia & GAL & 19905192 & 2670527 & 16525455 & 24788221 \\
\hline Madrid & MAD & 58951329 & 15540373 & 39896864 & 88534170 \\
\hline Murcia & MUR & 8406960 & 1943986 & 5795795 & 12324172 \\
\hline Navarra & NAV & 6164753 & 1404711 & 4340030 & 8743337 \\
\hline Rioja & RIO & 2863048 & 502635 & 2217832 & 3841215 \\
\hline Valencian Community & VAL & 35679308 & 6865198 & 27812822 & 49293679 \\
\hline Spain & ALL & 357426419 & 74179712 & 265079635 & 497902517 \\
\hline \multicolumn{6}{|c|}{ Labor } \\
\hline Andalusia & AND & 1537 & 238 & 1264 & 2087 \\
\hline Aragon & ARA & 381 & 39 & 328 & 472 \\
\hline Asturias & $\mathrm{AST}$ & 302 & 18 & 271 & 352 \\
\hline Balearic Islands & BAL & 236 & 67 & 159 & 359 \\
\hline Basque Country & PVA & 664 & 68 & 593 & 821 \\
\hline Canary Islands & $\mathrm{CAN}$ & 420 & 74 & 338 & 588 \\
\hline Cantabria & CANT & 148 & 17 & 130 & 186 \\
\hline Castilla-La Mancha & CMA & 455 & 53 & 404 & 583 \\
\hline Castilla-Leon & CLE & 725 & 43 & 651 & 824 \\
\hline Catalonia & CAT & 2081 & 366 & 1618 & 2833 \\
\hline Extremadura & EXT & 241 & 16 & 219 & 279 \\
\hline Galicia & GAL & 865 & 70 & 752 & 960 \\
\hline Madrid & MAD & 1488 & 319 & 1113 & 2168 \\
\hline Murcia & MUR & 286 & 48 & 233 & 399 \\
\hline Navarra & NAV & 185 & 31 & 153 & 249 \\
\hline Rioja & RIO & 91 & 11 & 77 & 116 \\
\hline Valencian Community & VAL & 1200 & 162 & 1019 & 1562 \\
\hline Spain & ALL & 11307 & 1470 & 9582 & 14661 \\
\hline \multicolumn{6}{|c|}{ Net Physical Capital } \\
\hline Andalusia & AND & 75566313 & 19056939 & 52397801 & 113700346 \\
\hline Aragon & ARA & 25873514 & 4918815 & 19508335 & 36492287 \\
\hline Asturias & $\mathrm{AST}$ & 17388384 & 2617594 & 13190890 & 21285198 \\
\hline Balearic Islands & BAL & 13485316 & 4884778 & 7700177 & 22463492 \\
\hline
\end{tabular}


Table 1 (Continued)

\begin{tabular}{|c|c|c|c|c|c|}
\hline Region & Code & Mean & $\begin{array}{l}\text { Standard } \\
\text { deviation }\end{array}$ & Minimum & Maximum \\
\hline Basque Country & PVA & 43735152 & 6341375 & 36512296 & 56812756 \\
\hline Canary Islands & CAN & 24272996 & 9651751 & 12815622 & 42514665 \\
\hline Cantabria & CANT & 7577494 & 1063742 & 6349618 & 9816363 \\
\hline Castilla-La Mancha & CMA & 25855232 & 5170927 & 17824522 & 35289395 \\
\hline Castilla-Leon & CLE & 39286720 & 6128817 & 30788730 & 51703042 \\
\hline Catalonia & CAT & 114072767 & 30371686 & 76177516 & 170846244 \\
\hline Extremadura & EXT & 17068648 & 1457109 & 13479261 & 19655413 \\
\hline Galicia & GAL & 32363138 & 7224086 & 23385409 & 46257380 \\
\hline Madrid & MAD & 69136554 & 30015697 & 38001093 & 133866241 \\
\hline Murcia & MUR & 13908458 & 4249517 & 9217925 & 22650872 \\
\hline Navarra & NAV & 12533978 & 3792093 & 8116629 & 19719503 \\
\hline Rioja & RIO & 5356895 & 1229479 & 3703426 & 7604587 \\
\hline Valencian Community & VAL & 50962487 & 14307497 & 32799796 & 79215087 \\
\hline Spain & ALL & 588444045 & 151807538 & 402618046 & 889892872 \\
\hline \multicolumn{6}{|c|}{ Human Capital Index } \\
\hline Andalusia & AND & 2.71 & 0.25 & 2.30 & 3.06 \\
\hline Aragon & ARA & 2.83 & 0.24 & 2.43 & 3.22 \\
\hline Asturias & AST & 2.79 & 0.24 & 2.43 & 3.17 \\
\hline Balearic Islands & BAL & 2.77 & 0.23 & 2.36 & 3.13 \\
\hline Basque Country & PVA & 2.96 & 0.25 & 2.57 & 3.34 \\
\hline Canary Islands & $\mathrm{CAN}$ & 2.75 & 0.22 & 2.37 & 3.09 \\
\hline Cantabria & CANT & 2.85 & 0.23 & 2.46 & 3.22 \\
\hline Castilla-La Mancha & CMA & 2.66 & 0.24 & 2.29 & 3.04 \\
\hline Castilla-Leon & CLE & 2.78 & 0.24 & 2.39 & 3.18 \\
\hline Catalonia & CAT & 2.87 & 0.23 & 2.50 & 3.20 \\
\hline Extremadura & $\mathrm{EXT}$ & 2.65 & 0.27 & 2.24 & 3.14 \\
\hline Galicia & GAL & 2.63 & 0.26 & 2.25 & 3.11 \\
\hline Madrid & MAD & 3.03 & 0.22 & 2.66 & 3.36 \\
\hline Murcia & MUR & 2.72 & 0.24 & 2.35 & 3.07 \\
\hline Navarra & NAV & 2.92 & 0.24 & 2.54 & 3.28 \\
\hline Rioja & RIO & 2.79 & 0.23 & 2.39 & 3.15 \\
\hline Valencian Community & VAL & 2.77 & 0.25 & 2.37 & 3.17 \\
\hline Spain & ALL & 2.81 & 0.24 & 2.43 & 3.18 \\
\hline
\end{tabular}


Table 2: Efficiency scores and percentage change of quadripartite decomposition indexes, 1980-2003

\begin{tabular}{|c|c|c|c|c|c|c|c|c|}
\hline$\#$ & Region & $\mathrm{TE}_{b}$ & $\mathrm{TE}_{c}$ & $\begin{array}{r}\text { productivity } \\
\text { change }\end{array}$ & $\begin{array}{r}\mathrm{EFF}-1 \\
\times 100\end{array}$ & $\begin{array}{r}\text { TECH }-1 \\
\times 100\end{array}$ & $\begin{array}{r}\mathrm{KACC}-1 \\
\times 100\end{array}$ & $\begin{array}{r}\mathrm{HACC}-1 \\
\times 100\end{array}$ \\
\hline 1 & Andalusia & 0.74 & 0.61 & 34.0 & -17.0 & 16.2 & 13.0 & 22.8 \\
\hline 2 & Aragon & 0.65 & 0.59 & 43.4 & -9.9 & 20.1 & 5.3 & 25.8 \\
\hline 3 & Asturias & 0.68 & 0.63 & 54.1 & -8.4 & 17.3 & 18.0 & 21.6 \\
\hline 4 & $\begin{array}{l}\text { Balearic Is- } \\
\text { lands }\end{array}$ & 1.00 & 0.62 & -0.7 & -37.5 & 18.8 & 9.1 & 22.6 \\
\hline 5 & $\begin{array}{l}\text { Basque } \\
\text { Country }\end{array}$ & 0.77 & 0.66 & 34.2 & -14.2 & 20.1 & 4.5 & 24.5 \\
\hline 6 & $\begin{array}{l}\text { Canary } \\
\text { Islands }\end{array}$ & 0.90 & 0.62 & 23.5 & -30.6 & 16.0 & 30.9 & 17.2 \\
\hline 7 & Cantabria & 0.67 & 0.65 & 48.8 & -2.5 & 15.4 & 10.7 & 19.5 \\
\hline 8 & $\begin{array}{l}\text { Castilla-La } \\
\text { Mancha }\end{array}$ & 0.62 & 0.53 & 38.6 & -14.6 & 18.4 & 11.3 & 23.1 \\
\hline 9 & $\begin{array}{l}\text { Castilla- } \\
\text { Leon }\end{array}$ & 0.63 & 0.58 & 52.4 & -7.8 & 18.1 & 13.5 & 23.4 \\
\hline 10 & Catalonia & 0.79 & 0.63 & 31.2 & -19.5 & 16.9 & 16.3 & 19.9 \\
\hline 11 & Extremadura & 0.48 & 0.50 & 73.6 & 3.1 & 20.1 & 2.8 & 36.4 \\
\hline 12 & Galicia & 0.67 & 0.57 & 74.6 & -13.6 & 11.8 & 54.6 & 17.0 \\
\hline 13 & Madrid & 1.00 & 0.72 & 26.8 & -28.4 & 12.0 & 40.9 & 12.2 \\
\hline 14 & Murcia & 0.75 & 0.59 & 30.3 & -21.8 & 16.1 & 18.3 & 21.3 \\
\hline 15 & Navarra & 0.74 & 0.62 & 29.2 & -16.3 & 20.1 & 6.5 & 20.7 \\
\hline 16 & Rioja & 0.75 & 0.61 & 29.9 & -18.7 & 18.5 & 10.4 & 22.1 \\
\hline 17 & $\begin{array}{l}\text { Valencian } \\
\text { Community }\end{array}$ & 0.85 & 0.63 & 25.6 & -25.5 & 13.2 & 31.3 & 13.5 \\
\hline & average & 0.75 & 0.61 & 38.2 & -16.7 & 17.0 & 17.5 & 21.4 \\
\hline & $\begin{array}{l}\text { weighted av- } \\
\text { erage }\end{array}$ & 0.77 & 0.62 & 36.2 & -18.8 & 15.9 & 21.8 & 19.8 \\
\hline
\end{tabular}


Table 3: Distribution hypothesis tests ( $p$-values)

\begin{tabular}{rlc}
\hline & $\mathrm{H}_{0}$ : Distributions are equal & $\begin{array}{c}\text { Bootstrap } \\
p \text {-value }\end{array}$ \\
\hline 1 & $g\left(y_{2003}\right)$ vs. $f\left(y_{1980}\right)$ & 0.0004 \\
2 & $g\left(y_{2003}\right)$ vs. $f\left(y_{1980} \times E F F\right)$ & 0.0000 \\
3 & $g\left(y_{2003}\right)$ vs. $f\left(y_{1980} \times T E C H\right)$ & 0.0480 \\
4 & $g\left(y_{2003}\right)$ vs. $f\left(y_{1980} \times K A C C\right)$ & 0.0060 \\
5 & $g\left(y_{2003}\right)$ vs. $f\left(y_{1980} \times H A C C\right)$ & 0.0658 \\
6 & $g\left(y_{2003}\right)$ vs. $f\left(y_{1980} \times E F F \times T E C H\right)$ & 0.0000 \\
7 & $g\left(y_{2003}\right)$ vs. $f\left(y_{1980} \times E F F \times K A C C\right)$ & 0.0000 \\
8 & $g\left(y_{2003}\right)$ vs. $f\left(y_{1980} \times E F F \times H A C C\right)$ & 0.0000 \\
9 & $g\left(y_{2003}\right)$ vs. $f\left(y_{1980} \times T E C H \times K A C C\right)$ & 0.1702 \\
10 & $g\left(y_{2003}\right)$ vs. $f\left(y_{1980} \times T E C H \times H A C C\right)$ & 0.8212 \\
11 & $g\left(y_{2003}\right)$ vs. $f\left(y_{1980} \times K A C C \times H A C C\right)$ & 0.7022 \\
12 & $g\left(y_{2003}\right)$ vs. $f\left(y_{1980} \times E F F \times T E C H \times K A C C\right)$ & 0.0000 \\
13 & $g\left(y_{2003}\right)$ vs. $f\left(y_{1980} \times E F F \times T E C H \times H A C C\right)$ & 0.0082 \\
14 & $g\left(y_{2003}\right)$ vs. $f\left(y_{1980} \times E F F \times K A C C \times H A C C\right)$ & 0.0000 \\
15 & $g\left(y_{2003}\right)$ vs. $f\left(y_{1980} \times T E C H \times K A C C \times H A C C\right)$ & 0.0122 \\
\hline
\end{tabular}

Notes: We used the bootstrapped LI $(1996)$ Tests with 5000 bootstrap replications and the SHEATHER and JONES (1991) bandwidth. 
Table 4: Efficiency scores and percentage change of quadripartite decomposition indexes. Sectoral analysis

\begin{tabular}{|c|c|c|c|c|c|c|c|}
\hline Region & $\mathrm{TE}_{b}$ & $\mathrm{TE}_{c}$ & $\begin{array}{r}\text { productivity } \\
\text { change }\end{array}$ & $\begin{array}{r}\mathrm{EFF}-1 \\
\times 100\end{array}$ & $\begin{array}{r}\text { TECH-1 } \\
\times 100\end{array}$ & $\begin{array}{r}\mathrm{KACC}-1 \\
\times 100\end{array}$ & $\begin{array}{r}\mathrm{HACC}-1 \\
\times 100\end{array}$ \\
\hline \multicolumn{8}{|c|}{ Total Industry } \\
\hline $1980-2003$ & 0.77 & 0.62 & 36.2 & -18.8 & 15.9 & 21.8 & 19.8 \\
\hline $1980-1994$ & 0.77 & 0.69 & 38.3 & -9.4 & 16.2 & 17.5 & 12.4 \\
\hline $1995-2003$ & 0.69 & 0.62 & -2.2 & -9.7 & 0.0 & 1.9 & 6.3 \\
\hline \multicolumn{8}{|c|}{ Agriculture } \\
\hline $1980-2003$ & 0.77 & 0.72 & 197.2 & -5.0 & 96.6 & 38.0 & 18.3 \\
\hline 1980-1994 & 0.77 & 0.66 & 126.1 & -14.1 & 80.4 & 34.8 & 11.0 \\
\hline $1995-2003$ & 0.62 & 0.72 & 44.4 & 24.2 & 7.2 & 1.8 & 5.9 \\
\hline \multicolumn{8}{|c|}{ Manufacturing } \\
\hline $1980-2003$ & 0.83 & 0.84 & 63.5 & 2.4 & 18.7 & 12.4 & 21.3 \\
\hline 1980-1994 & 0.83 & 0.87 & 46.0 & 6.0 & 13.3 & 8.2 & 13.4 \\
\hline $1995-2003$ & 0.88 & 0.84 & 9.3 & -4.8 & 5.8 & -0.2 & 8.9 \\
\hline \multicolumn{8}{|c|}{ Construction } \\
\hline $1980-2003$ & 0.85 & 0.58 & 2.96 & -31.49 & 22.59 & 8.36 & 13.72 \\
\hline 1980-1994 & 0.85 & 0.70 & 26.91 & -16.55 & 21.30 & 13.41 & 11.26 \\
\hline $1995-2003$ & 0.70 & 0.58 & -19.2 & -18.0 & 0.0 & -5.5 & 4.2 \\
\hline \multicolumn{8}{|c|}{ Energy } \\
\hline $1980-2003$ & 0.63 & 0.63 & 117.6 & 7.4 & 44.8 & 13.1 & 26.8 \\
\hline $1980-1994$ & 0.63 & 0.55 & 69.2 & -7.9 & 43.7 & 9.7 & 17.9 \\
\hline $1995-2003$ & 0.55 & 0.63 & 29.0 & 17.7 & 0.3 & 1.6 & 8.0 \\
\hline \multicolumn{8}{|c|}{ Services } \\
\hline $1980-2003$ & 0.92 & 0.48 & 4.2 & -47.6 & 9.4 & 54.1 & 18.6 \\
\hline $1980-1994$ & 0.92 & 0.63 & 10.6 & -31.4 & 7.3 & 38.0 & 9.2 \\
\hline $1995-2003$ & 0.62 & 0.48 & -6.2 & -21.4 & 0.0 & 15.1 & 4.0 \\
\hline
\end{tabular}


Table 5: Sources of Productivity Growth, 1980-2003

\begin{tabular}{|c|c|c|c|c|c|c|c|c|c|c|c|c|}
\hline \multirow[b]{2}{*}{ Region } & \multicolumn{4}{|c|}{ Panel A: Full Period } & \multicolumn{4}{|c|}{ Panel B: Subperiod 1980-1994 } & \multicolumn{4}{|c|}{ Panel C: Subperiod 1995-2004 } \\
\hline & PGE & $\mathrm{SE}$ & $\mathrm{DE}$ & $\mathrm{TE}$ & PGE & $\mathrm{SE}$ & $\mathrm{DE}$ & $\mathrm{TE}$ & PGE & $\mathrm{SE}$ & $\mathrm{DE}$ & $\mathrm{TE}$ \\
\hline Andalusia & 32.24 & 12.23 & -10.52 & 33.95 & 32.77 & 11.87 & -4.44 & 40.20 & -1.91 & -0.53 & -1.52 & -3.97 \\
\hline Aragon & 43.29 & 10.41 & -10.31 & 43.39 & 37.41 & 7.83 & 0.61 & 45.85 & -0.40 & 0.87 & -3.45 & -2.98 \\
\hline Asturias & 48.49 & 23.62 & -18.00 & 54.11 & 22.78 & 16.44 & 0.89 & 40.11 & 8.50 & 5.97 & -7.71 & 6.77 \\
\hline Balearic Islands & -4.98 & 16.96 & -12.71 & -0.73 & 13.57 & 21.40 & -7.04 & 27.93 & -16.00 & -2.32 & -2.14 & -20.45 \\
\hline Basque Country & 39.61 & 7.37 & -12.80 & 34.18 & 33.09 & 8.22 & -5.53 & 35.79 & 0.90 & -1.60 & -1.61 & -2.30 \\
\hline Canary Islands & 20.01 & 11.41 & -7.91 & 23.51 & 25.77 & 8.81 & 0.17 & 34.75 & -5.70 & 2.54 & -3.24 & -6.41 \\
\hline Cantabria & 42.31 & 20.14 & -13.65 & 48.80 & 38.33 & 18.79 & -2.57 & 54.55 & -1.00 & -1.73 & -3.41 & -6.13 \\
\hline Castilla-la-Mancha & 39.15 & 9.06 & -9.61 & 38.61 & 46.82 & 12.47 & -9.11 & 50.18 & -6.11 & -1.67 & -0.68 & -8.46 \\
\hline Castilla-Leon & 51.27 & 25.05 & -23.90 & 52.42 & 31.67 & 24.75 & -11.96 & 44.46 & 3.48 & -1.10 & -1.35 & 1.03 \\
\hline Catalonia & 33.20 & 6.33 & -8.25 & 31.27 & 36.32 & 4.68 & -2.28 & 38.72 & -4.65 & -0.65 & -1.23 & -6.53 \\
\hline Extremadura & 76.11 & 20.36 & -22.84 & 73.63 & 56.06 & 26.89 & -14.11 & 68.85 & 8.81 & -2.76 & -0.77 & 5.28 \\
\hline Galicia & 56.38 & 44.53 & -26.28 & 74.64 & 22.94 & 22.32 & -5.71 & 39.55 & 10.67 & 13.22 & -6.96 & 16.93 \\
\hline Madrid & 29.12 & 9.33 & -11.64 & 26.81 & 29.26 & 7.27 & -3.81 & 32.71 & -2.07 & 0.01 & -2.37 & -4.43 \\
\hline Murcia & 28.80 & 12.43 & -10.95 & 30.28 & 25.12 & 9.48 & -4.12 & 30.47 & 0.84 & -0.02 & -1.82 & -1.00 \\
\hline Navarra & 33.82 & 10.39 & -15.01 & 29.19 & 32.98 & 8.14 & -6.18 & 34.94 & -1.34 & -0.66 & -2.86 & -4.87 \\
\hline Rioja & 33.77 & 13.16 & -17.03 & 29.90 & 31.49 & 12.95 & -11.73 & 32.71 & 1.57 & -0.45 & -3.91 & -2.80 \\
\hline Valencian Community & 22.62 & 11.77 & -8.84 & 25.55 & 18.12 & 8.81 & -1.78 & 25.15 & 2.31 & 1.02 & -1.94 & 1.39 \\
\hline Spain & 35.23 & 14.05 & -12.43 & 36.85 & 30.30 & 11.59 & -3.35 & 38.55 & -0.43 & 0.28 & -2.00 & -2.15 \\
\hline
\end{tabular}

PGE refers to the intrasectoral productivity growth effect, SE stands for the static share effect, DE represents the dynamic effect and TE the total effect. 